\title{
Avaliação vocal de pacientes portadores de obesidade mórbida candidatos à cirurgia bariátrica
}

Dissertação apresentada à Faculdade de Medicina da Universidade de São Paulo para obtenção do título de Mestre em Ciências

Área de Concentração: Cirurgia do Aparelho Digestivo

Orientador: Prof. Dr. Bruno Zilberstein

São Paulo

2008 


\section{Avaliação vocal de pacientes portadores de obesidade mórbida candidatos à cirurgia bariátrica}

Maria Gabriela Bernardo da Cunha

Presidente da banca: Prof.(a) Dr.(a)

BANCA EXAMINADORA

Prof.(a) Dr.(a)

Prof.(a) Dr.(a)

Prof.(a) Dr.(a) 


\section{DEDICATÓRIA}

Dedico este trabalho aos meus pais, Otavio e Maria Emilia, por terem me dado a oportunidade de chegar até aqui, com incentivo e sempre torcendo por mim, acreditando na minha carreira.

Aos meus avós, Emídio e Clara, por se orgulharem da neta mais velha e, principalmente, por estarem sempre ao meu lado com palavras carinhosas e de apoio. 


\section{AGRADECIMENTO ESPECIAL}

Ao Dr. Gustavo Haruo Passerotti, pela ajuda, paciência e companheirismo durante todo este trabalho, que foram imprescindíveis. Sem as suas contribuições tudo teria sido mais difícil. Obrigada por tudo e pela colaboração ao atendimento dos pacientes. 


\section{AGRADECIMENTOS}

Ao Prof. Dr. Bruno Zilberstein, um exemplo de seriedade e conhecimento. Agradeço às orientações ao longo deste trabalho.

Ao Prof. Dr. Domingos Hiroshi Tsuji, pelo incentivo em realizar este estudo em outra disciplina, e por todos os ensinamentos na área de Laringologia e Voz.

Aos médicos da Clínica Otorrinolaringológica pelo incentivo e apoio.

Ao Prof. Dr. Ivan Ceconello pela oportunidade e credibilidade dadas a mim.

Ao amigo Dr. Raimar Weber, por todas as horas dedicadas a este estudo e pela realização das análises estatísticas.

Ao Dr. Luiz Antonio Prata Figueiredo, por agüentar meus desabafos e pela ajuda desprendida durante todo este trabalho. 
Às Fonoaudiólogas e amigas, Maysa Tibério Ubrig e Márcia Menezes, pela amizade, disponibilidade e ajuda na etapa da análise perceptivo-auditiva.

À Fonoaudióloga Flavia Arcos, pela ajuda na gravação das vozes.

À Fonoaudióloga Gislaine Cordeiro pelas dicas e ensinamentos na etapa da análise acústica.

Às Fonoaudiólogas Bete Pedalini, Valéria Goffi, Maria Lúcia Cleto, Flavia Bonadia, Laura Garcia Vasconcellos, Cristina Fúria, Mariana Cardoso Guedes, pela amizade, apoio e reconhecimento.

À Profa. Dra. Sílvia Pinho, por todos os ensinamentos durante toda a minha formação na área da Voz que estimularam a ampliação do meu conhecimento e desenvolvimento profissional. 
À Psicóloga Dra. Marlene, pelas idéias e incentivos nesta área, até então, desconhecida por mim.

Aos meus irmãos, Maria Eugenia e Otavio, e aos meus cunhados, Eduardo e Silmara, pelos incentivos mesmo sem eles saberem. Nanny, obrigada por tudo!

Ao meu querido sobrinho Bernardo, que no momento do seu nascimento até os dias de hoje, só me trouxe alegria e garra para continuar lutando por aquilo que desejo. E aos meus dois novos sobrinhos, Gabriel e Murilo que acabaram de chegar!

Às minhas amigas, Patrícia Diniz, Priscila Diniz e Melissa Leonel, que sempre estiveram ao meu lado nos momentos mais difíceis que passei.

À minha prima Camila Botelho, que me ajudou a superar a dor nos dias em que eu queria desistir de tudo. Muito obrigada. 
Ao Prof. Dennis Cintra Leite pela ajuda e pela tradução do trabalho para o inglês.

Às queridas Vilma e Myrtes, da pós graduação. Obrigada por tudo!

Às meninas da secretaria da Disciplina do Aparelho Digestivo, sempre presentes e prestativas.

Aos pacientes, pela inspiração e participação, já que sem isso não seria possível a realização deste estudo. 


\section{NORMALIZAÇÃO ADOTADA}

Esta dissertação está de acordo com as seguintes normas, em vigor no momento desta publicação:

Referências: adaptado de International Committee of Medical Journals Editors (Vancouver).

Universidade de São Paulo. Faculdade de Medicina. Serviço de Biblioteca e Documentação. Guia de apresentação de dissertações, teses e monografias. Elaborado por Annelise Carneiro da Cunha, Maria Julia de A. L. Freddi, Maria F. Crestana, Marinalva de Souza Aragão, Suely Campos Cardoso, Valéria Vilhena. $2^{a}$ ed. São Paulo: Serviço de Biblioteca de Documentação; 2005.

Abreviaturas dos títulos dos periódicos de acordo com List of Journals Indexed in Index Medicus. 


\section{SUMÁRIO}

Lista de abreviaturas, símbolos e siglas

Lista de figuras

Lista de tabelas

Resumo

Summary

Normas para publicação

1. INTRODUÇÃO ....................................................... 1

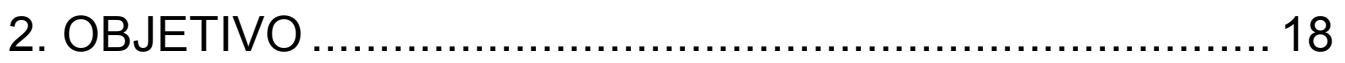

3. CASUÍSTICA E MÉTODOS .......................................... 19

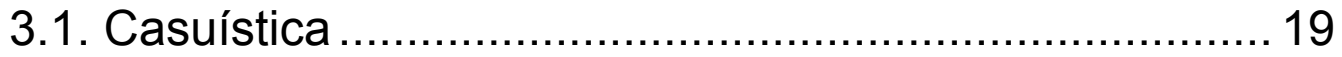

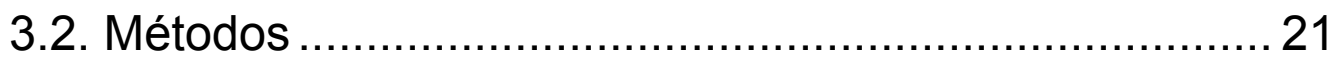

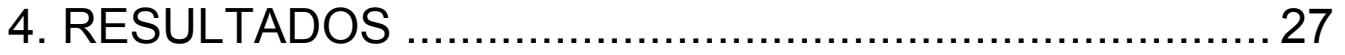

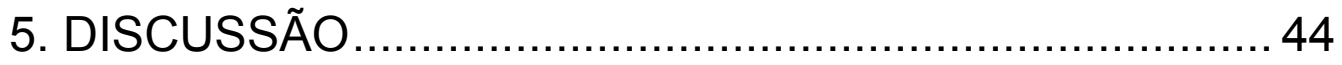

6. CONCLUSÕES ...................................................... 53

7. REFERÊNCIAS BIBLIOGRÁFICAS ............................. 54

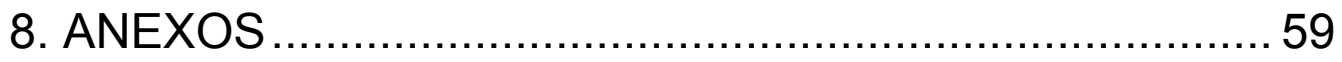




\section{LISTA DE ABREVIATURAS, SÍMBOLOS E SIGLAS}

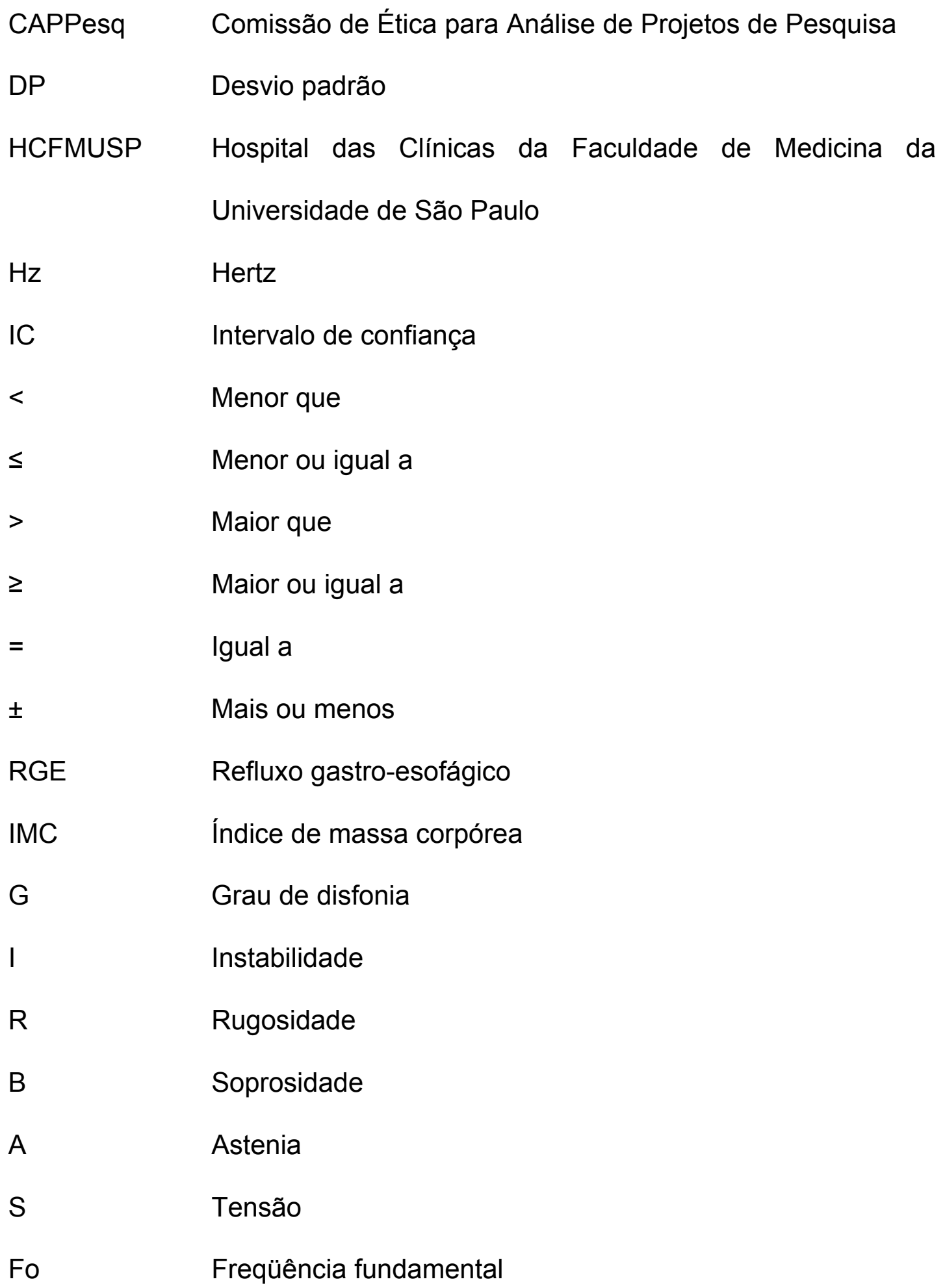




$\begin{array}{ll}\text { pv } & \text { Prega Vocal } \\ \mathrm{dB} & \text { Decibel } \\ \text { TMF } & \text { Tempo máximo fonatório } \\ \text { VAS } & \text { Vias aéreas superiores } \\ \text { SAHOS } & \text { Síndrome da Apnéia e Hipopnéia Obstrutiva do Sono } \\ \mathrm{Kg} & \text { Kilograma } \\ \mathrm{Kg} / \mathrm{m}^{2} & \text { Kilograma por metro quadrado } \\ \mathrm{m} & \text { Metro } \\ \mathrm{n} & \text { Número } \\ \text { cig/dia } & \text { Cigarros por dia } \\ \text { seg } & \text { Segundos } \\ \mathrm{RR} & \text { Risco relativo } \\ \mathrm{GO} & \text { Grupo de obesos } \\ \mathrm{GC} & \text { Grupo controle }\end{array}$




\section{LISTA DE FIGURAS}

Figura 1 - Médico Laringologista realizando exame vídeo-estrobolaringoscópico

Figura 2 - Gravação da voz no computador em cabina acústica

Figura 3 - Prevalências dos graus 0, 1 e 2 de disfonia entre os grupos obesos e controles.

Figura 4 - Prevalências dos graus 0,1 e 2 de instabilidade entre os grupos obesos e controles.

Figura 5 - Prevalências dos graus 0,1 e 2 de rouquidão entre os grupos obesos e controles.

Figura 6 - Prevalências dos graus 0,1 e 2 de soprosidade entre os grupos obesos e controles.

Figura 7 - Prevalências dos graus 0,1 e 2 de astenia entre os grupos obesos e controles.

Figura 8 - Prevalências dos graus 0, 1 e 2 de tensão entre os grupos obesos e controles

Figura 9 - Prevalência de "Vocal fry", Estrangulamento e Ressonância não equilibrada entre os grupos obesos e controles

Figura 10 - Boxplot da Freqüência Fundamental $(\mathrm{Hz})$ entre os grupos de obesos e controles agrupados de acordo com o sexo

Figura 11 - Prevalência de "Jitter", "Shimmer" e Ruído alterados entre os grupos obesos e controles.

Figura 12 - Boxplot do Tempo Máximo Fonatório (segundos) entre os grupos de obesos e controles agrupados de acordo com o sexo....

Figura 13 - Prevalências dos graus 0, 1 e 2 de disfonia entre os grupos obesos e controles, após exclusão de 16 pares obeso-controle que apresentavam lesões à laringoscopia

Figura 14 - Prevalências dos graus 0, 1 e 2 de instabilidade entre os grupos obesos e controles, após exclusão de 16 pares obeso-controle que apresentavam lesões à laringoscopia 
Figura 15 - Prevalências dos graus 0,1 e 2 de rouquidão entre os grupos obesos e controles, após exclusão de 16 pares obeso-controle que apresentavam lesões à laringoscopia

Figura 16 - Prevalências dos graus 0,1 e 2 de soprosidade entre os grupos obesos e controles, após exclusão de 16 pares obeso-controle que apresentavam lesões à laringoscopia .38

Figura 17 - Prevalências dos graus 0, 1 e 2 de disfonia entre os grupos obesos e controles, após exclusão de 16 pares obeso-controle que apresentavam lesões à laringoscopia

Figura 18 - Prevalências dos graus 0,1 e 2 de tensão entre os grupos obesos e controles, após exclusão de 16 pares obeso-controle que apresentavam lesões à laringoscopia

Figura 19 - Prevalência de "Vocal fry", Estrangulamento e Ressonância não equilibrada entre os grupos obesos e controles, após a exclusão de 16 pares obeso-controle com lesões laríngeas à laringoscopia 40

Figura 20 - Boxplot da Freqüência Fundamental $(\mathrm{Hz})$ entre os grupos de obesos e controles agrupados de acordo com o sexo, após exclusão de 16 pares obeso-controle que apresentavam lesões à laringoscopia

Figura 21 - Prevalência de "Jitter", "Shimmer" e Ruído alterados entre os grupos obesos e controles, após exclusão de 16 pares obesocontrole que apresentavam lesões à laringoscopia

Figura 22 - Boxplot do Tempo Máximo Fonatório (segundos) entre os grupos de obesos e controles agrupados de acordo com o sexo, após exclusão de 16 pares obeso-controle que apresentavam lesões à laringoscopia 


\section{LISTA DE TABELAS}

Tabela 1 - Dados demográficos dos indivíduos estudados

Tabela 2 - Achados Laringoscópicos.

Tabela 3 - Prevalências dos graus 0, 1, 2 e 3 de GIRBAS entre Go e GC..28

Tabela 4 - Prevalência de "Vocal fry", Estrangulamento e Ressonância não equilibrada entre GO e GC.

Tabela 5 - Prevalências de Freqüência Fundamental, "Jitter", "Shimmer", Ruído e Tempo Máximo fonatório entre GO e GC

Tabela 6 - Análise perceptivo-auditiva dos indivíduos estudados, após exclusão de 16 pares obeso-controle que apresentavam lesões à laringoscopia 36

Tabela 7 - Prevalência de "Vocal fry", Estrangulamento e Ressonância não equilibrada entre os grupos obesos e controles, após a exclusão de 16 pares obeso-controle com lesão de laringe à laringoscopia .......................................................... 40

Tabela 8 - Análise acústica dos indivíduos estudados sem lesões laríngeas

Tabela 9 - Análise da força de associação (risco relativo) das alterações perceptivo-auditivas e acústicas da voz e obesidade em relação ao grupo controle 


\section{RESUMO}

A obesidade é uma endemia, com prevalência estimada, entre os anos de 1989 e 1994, de quase 40\% na população norte-americana e $20 \%$ na população brasileira, que traz diversos problemas de saúde no seu contexto biopsicossocial. Dentre essas comorbidades discute-se a característica da voz destes indivíduos. O objetivo deste estudo foi caracterizar os parâmetros vocais dos indivíduos portadores de obesidade mórbida, comparado-os aos de indivíduos não obesos, através da análise acústica e perceptivo-auditiva no sentido de caracterizar seu padrão vocal. Método: Foram selecionados 45 indivíduos adultos voluntários do Ambulatório de Obesidade da Disciplina de Cirurgia do Aparelho Digestivo, de ambos os sexos com IMC acima de $35 \mathrm{Kg} / \mathrm{m}^{2}$. Para cada indivíduo do grupo em estudo, foi selecionado também um individuo adulto voluntário, pareado por sexo, idade e tabagismo, porém com IMC abaixo de $30 \mathrm{Kg} / \mathrm{m}^{2}$. Todos os indivíduos foram submetidos a exame laringológico e à gravação da voz no Setor de Fonoaudiologia do Ambulatório de Otorrinolaringologia. Foi realizada análise estatística onde os valores de $p$ menores que 0,05 foram considerados estatisticamente significantes. Os resultados mostraram que os indivíduos portadores de obesidade mórbida apresentaram mais frequentemente: sinais laríngeos sugestivos de lesão por RGE; 4 vezes mais rouquidão, 3 vezes mais instabilidade, 5 vezes mais soprosidade; 5 vezes mais estrangulamento aos finais das emissões; "Jitter", "Shimmer" e Ruído alterados e Tempos Máximos Fonatórios inferiores em relação aos indivíduos do grupo controle. Concluiu-se que o indivíduo portador de obesidade mórbida tem sua voz caracterizada como: rouca, soprosa e com instabilidade fonatória, com "Jitter" e "Shimmer" alterados, TMF diminuídos e com presença de estrangulamento da voz ao final das emissões.
Descritores: 1) Distúrbios da Voz
Fala 4) Rouquidão
2) Obesidade Mórbida
3) Acústica da 


\section{SUMMARY}

Obesity is an endemic illness whose estimated prevalence, from 1989 to 1994, was $40 \%$ amongst North American people and $20 \%$ amongst Brazilian people. It is a disease that causes several health problems on a biopsychosocial basis. Amongst these consequences of obesity, the voice characteristics of affected people is a target of discussion and analysis. The purpose of this study was to set the voice patterns of people affected by morbid obesity, by making a comparison to the voice patterns of people who are not fat. The comparison was made through the acoustic and auditoryperceptive analysis in order to establish the voice patterns. Method: We have selected 45 adults who are volunteers coming from the Center for Obesity Specialized in the Digestive System Surgery. The selected people were men and women whose Body Mass Index (BMI) is higher than $35 \mathrm{~kg} /$ $\mathrm{m}^{2}$. For each person selected, there is another one, also adult, same sex, age and smoking habit, but with a BMI under than $30 \mathrm{~kg} / \mathrm{m}^{2}$. All the volunteers made laryngology test and their voice was recorded in the Phonoaudiology Department, from the Center of Otorhinolaryngology. We prepared the statistics, disregarding the values under 0.05 , considered statistically insignificant. The results showed that the patients affected by morbid obesity presented more frequently: signs on their larynx that indicate gastroesophageal reflux (GER); 4 (four) times more hoarseness, 3 (three) times more instability, 5 (five) times more vocal fatigue and breathing; 5 (five) times more voice cracking. Besides these disabilities, people affected by morbid obesity presented changes in Jitter, Shimmer and Noise, as well as low Maximum Phonation Time (MPT). We conclude that people affected by morbid obesity present roughness, breathness with phonatory instability, changes in Jitter and Shimmer, low MPT and cracking voice.

Descriptors: 1) Voice Disorders

4) Hoarseness

2) Obesity Morbid

3) Speech Acoustics 


\section{1- INTRODUÇÃO}

A voz é o produto do ar expirado pelos pulmões, que se sonoriza nas pregas vocais e é modificado pelas cavidades de ressonância como faringe, cavidade oral e nasal e por estruturas como os lábios, a língua e o palato.

Segundo ARONSON, 1985, a fonação é um ato físico de produção do som por meio da interação das pregas vocais com a corrente de ar exalada. Os puffs de ar são liberados em freqüência audível, ressoando nas cavidades supraglóticas. Para o mesmo autor, os atributos da voz normal são: pitch (sensação subjetiva da freqüência) adequado à idade e sexo, loudness (sensação subjetiva da intensidade) adequado ao ambiente, qualidade agradável e sem ruídos (relativo à ressonância e ruídos glóticos), flexibilidade com expressões de ênfase, significado e sutilezas (interação de todos os anteriores).

A disfonia é, por definição, um sintoma caracterizado como "uma dificuldade na emissão da voz com suas características naturais" (TARNEAUD, 1941).

Segundo PINHO, 1998, existem três formas etiológicas de disfonias: funcionais, orgânicas secundárias e orgânicas primárias. As funcionais caracterizam-se pela presença de distúrbio vocal na ausência de alterações 
orgânicas significativas. As orgânicas secundárias também são decorrentes do uso indevido da voz, mas já apresenta alterações orgânicas como conseqüência. E as disfonias orgânicas primárias, aquelas cujo estabelecimento independe do uso indevido da voz.

Os pacientes portadores de disfonia que procuram auxílio geralmente são avaliados pelo médico otorrinolaringologista que estabelece o diagnóstico, determinando o tratamento mais adequado.

A avaliação fonoaudiológica de um paciente com distúrbio vocal inicia-se com anamnese cuidadosa, onde são investigados dados sobre identificação, queixas atuais, sintomas associados, quadro evolutivo e estado de saúde geral que auxiliarão na determinação do melhor plano terapêutico.

Parte importante desse processo é a avaliação perceptivo-auditiva que, quando feita por profissional experiente, pode ser de fundamental importância para o diagnóstico correto e tratamento mais adequado. Segundo COLTON \& CASPER (1996), é apropriado fazer um julgamento perceptual da qualidade vocal, porém tais julgamentos devem ser feitos com cautela. A avaliação perceptivo-auditiva é a avaliação clássica da qualidade vocal, tradicional da rotina clínica (BEHLAU et al., 2001). 
Para COLTON \& CASPER (1996), as estratégias utilizadas na avaliação perceptivo-auditiva envolvem a comparação de vozes a um sistema de referência pessoal do avaliador, sendo este instável e flutuante, podendo causar variação nas avaliações. Os mesmos autores reconhecem a dificuldade para definir algumas características vocais e revelam ainda a dificuldade para descrever verbalmente as percepções que são subjetivas, individuais, sendo influenciadas por preferências pessoais, experiências e culturas diferentes.

Segundo COLTON \& CASPER (1996), os sinais perceptuais da voz são: pitch (correlato perceptual da freqüência fundamental), loudness (correlato perceptual da intensidade), qualidade vocal, comportamento nãofonatório (como, por exemplo, tosse e pigarro) e afonia (ausência de fonação).

Segundo BEHLAU, 2001, a avaliação perceptivo-auditiva pode ser de caráter exclusivamente impressionístico (voz rouca, soprosa, comprimida, etc.), o que tem sido uma preferência clínica internacional, ou envolver diversas escalas e índices para uma determinação menos subjetiva e mais confiável do desvio encontrado.

A qualidade vocal é por outro lado a descrição mais complexa, pois são usados adjetivos difíceis de quantificar e também por não haver concordância amplamente difundida sobre os sentidos dos termos. 
A escala japonesa de qualidade vocal (GRBAS), amplamente difundida por HIRANO (1981), é baseada nos trabalhos de ISSHIKI, 1966 sobre rouquidão. Em 1996, DEJONCKERE, REMACLE \& FRESNELELBAZE propuseram que se acrescentasse o fator I, de instabilidade. Esta escala (GIRBAS) foi desenvolvida para padronização da avaliação psicoacústica de vozes patológicas. Ela é particularmente centrada em nível laríngeo, mas oferece uma avaliação rápida, compacta e confiável, tendo-se transformado na escala mais utilizada internacionalmente. Esta escala é um método simples de avaliação do grau da disfonia $(G)$ pela identificação de quatro parâmetros isolados: rugosidade - irregularidade de vibração das pregas vocais (R-roughness); instabilidade - flutuação na qualidade vocal (Iinstability); soprosidade - escape de ar transglótico não sonorizado (Bbreathness); astenia - fraqueza vocal, perda de potência com harmônicos pouco definidos (A-asteny); e tensão - compressão das pregas vocais na linha média (S-strain); considerados os mais importantes na definição de uma voz disfônica.

Dentre os mecanismos responsáveis pela formação da voz há ainda o sistema de ressonância vocal que é o conjunto de elementos do aparelho fonador que guardam íntima relação entre si, visando à modelagem e à projeção do som no espaço. A ressonância consiste no esforço da intensidade de sons de determinadas freqüências do espectro sonoro e no amortecimento de outras. Segundo BEHLAU, 2001, a ressonância equilibrada apresenta riqueza de harmônicos amplificados na voz. O uso 
excessivo da laringe confere à emissão uma característica tensa, e identifica-se o foco vertical de ressonância como baixo. A voz parece estar presa na garganta e não apresenta riqueza de harmônicos e projeção adequada no ambiente. Também o uso excessivo da faringe confere à emissão uma característica tensa, mas o foco vertical não se apresenta tão baixo e é geralmente acompanhado de uma característica metálica na voz, pela reflexão do som nas paredes rígidas da faringe. Pode haver tensionamento conjunto dessas duas regiões, e a ressonância neste caso denomina-se laringo-faríngea. $\mathrm{O}$ uso excessivo (hipernasal) ou insuficiente (hiponasal) da cavidade do nariz confere à emissão uma ressonância de foco vertical alto (BEHLAU, 2001).

Ainda dentro da formação da voz, SATALOFF (1987) ressalta, em seu estudo, a importância dos ressoadores (laringe, supraglote, lábios, palato, faringe, cavidade nasal e seios paranasais) para a qualidade do som produzido, e este fenômeno é caracterizado pelas pequenas alterações realizadas em sua configuração.

ZEMLIN (1988) relata em seu estudo que a ressonância é determinada pela forma e pelo comprimento do trato vocal, ou seja, quando o trato vocal é longo, a ressonância é mais baixa e, quando encurtado, mais alta. 
ESTILL (1992) descreve os ajustes laríngeos e do trato vocal necessários para a produção de vozes com características de ressonância baixa e alta. A fim de obter uma ressonância baixa, o trato vocal deve permanecer expandido, a laringe deve estar baixa, a língua elevada e relaxada. Na ressonância alta, segundo a autora, o trato vocal deve ser curto e a língua deve permanecer baixa e relaxada.

Ainda na avaliação perceptivo-auditiva da voz levamos em conta o "vocal fry" e o estrangulamento.

O "vocal fry" corresponde à região mais grave da extensão vocal, abrangendo uma faixa de freqüências de 30 a 75 Hz (HIRANO \& BLESS, 1993). Fisiologicamente, é produzido com pouco fluxo de ar e atividade predominantemente do músculo tirearitenóideo. A voz tem uma qualidade crepitante e sua freqüência vocal é bastante grave.

O estrangulamento da voz ao final da emissão significa que a voz está tensa. A vibração da mucosa das pregas vocais é de pouca extensão. Isto pode estar associado ao tempo máximo de fonação reduzido aonde o fluxo de ar vai diminuindo e o indivíduo faz uma certa força estrangulando assim, o final da emissão.

Atualmente, dados objetivos da qualidade vocal têm sido determinados pela avaliação acústica computadorizada, onde se podem 
obter informações objetivas dos parâmetros vocais. Esses dados podem ser utilizados para a avaliação da própria voz e da eficácia terapêutica no tratamento da disfonia. Entretanto, por mais completa que seja a análise acústica realizada, os dados numéricos obtidos dificilmente são capazes de substituir por completo a avaliação perceptivo-auditiva do examinador e do próprio paciente.

Esta última forma de avaliação da qualidade vocal, ainda que sujeita a diversas variáveis de difícil documentação, pode ser considerada como um método sempre utilizado durante qualquer contato entre o profissional de saúde (médico ou não) e o paciente, seja no período pré-tratamento ou póstratamento.

São avaliados na análise acústica, de modo geral, a freqüência fundamental, harmônicos, "jitter", "shimmer", ruído e tempo máximo fonatório.

A Freqüência corresponde ao número de ondas que ocorrem num dado intervalo de tempo. O sinal laríngeo é constituído de uma freqüência principal (Freqüência Fundamental-Fo ou primeiro harmônico), de maior amplitude produzida concomitantemente com freqüências adicionais, múltiplas inteiras desta, que caracterizam os demais harmônicos (PINHO e CAMARGO, 2001). 
Na vibração glótica normal há produção de diversos harmônicos. Dizemos que a voz é pobre em harmônicos quando a amplitude destes está muito reduzida, muitas vezes não sendo captada a estrutura harmônica nos gráficos de análise acústica. Em condições vocais e laríngeas normais, os harmônicos tendem a perder por volta de $12 \mathrm{~dB}$ por oitava em sua energia assim que as freqüências avançam em direção aos agudos. Por essa razão, em análise acústica geralmente se consideram mais importantes os harmônicos até 5.000 Hz; acima desse limite, passam a ter amplitudes tão pequenas que costumam ser desprezados para o estudo clínico da voz. Entretanto, enfatizamos que faixas maiores de análise de freqüência (até 10.000 Hz) são fundamentais na identificação de zonas de ruído de alta freqüência observadas diante de vários graus de afecções vocais (PINHO \& CAMARGO, 2001).

Segundo BEHLAU, TOSI, PONTES (1985), a freqüência fundamental média, para falantes do português brasileiro, para adultos do sexo masculino é de $113 \mathrm{~Hz}$ e para adultos do sexo feminino é de $204 \mathrm{~Hz}$.

O "jitter" é uma medida de perturbação em torno do parâmetro físico de freqüência. O "jitter" indica a variabilidade da freqüência fundamental a curto prazo, medida entre ciclos glóticos vizinhos. Os valores de "jitter" em indivíduos normais podem representar uma pequena variação na massa ou na tensão das pregas vocais (BAKEN, 1987). Entretanto, quando lesões afetam as pregas vocais, suas vibrações mostram um aumento na 
aperiodicidade, o que é refletido em valores aumentados de "jitter". As medidas relativas de "jitter" são expressas em porcentagem e o valor limite da normalidade é $0,5 \%$ (BEHLAU, 2001). BEHLAU refere que, havendo lesões que afetam as pregas vocais, suas vibrações mostram aumento na aperiodicidade, o que é refletido em valores aumentados de "jitter".

O "shimmer" indica a variabilidade da amplitude da onda sonora a curto prazo e é uma medida de estabilidade fonatória. O "shimmer" representa as alterações irregulares na amplitude dos ciclos glóticos, de um ciclo a outro. Como o "jitter", o "shimmer" tende a ser geralmente elevado nos distúrbios laríngeos, apresentando também maiores valores nas freqüências graves e de baixa intensidade. Todas as medidas relativas de "shimmer" são oferecidas em porcentagem e seu valor limite é de $3 \%$ (BEHLAU, 2001).

As medidas de ruído foram desenvolvidas na tentativa de quantificar o ruído visível nas representações espectrográficas (PINHO \& CAMARGO, 2001). A importância dessas medidas reside no fato de que o ruído acústico parece ser um excelente correlato do que o nosso ouvido considera como disfonia. As vozes normais apresentam certa quantidade de ruído esperada, relacionada às perturbações da produção da voz (BEHLAU, 2001).

O tempo máximo de fonação (TMF) é uma medida acústica. É um dos parâmetros com que se obtém de modo mais fácil as medidas respiratórias. 
Esse valor é obtido pela medida do tempo máximo que um indivíduo consegue sustentar uma emissão de um som, numa só expiração, e permite uma investigação quantitativa e qualitativa da fonação.

O teste de vogais sustentadas, em freqüência e intensidade habituais, indica a habilidade do paciente em controlar as forças aerodinâmicas da corrente pulmonar e as forças mioelásticas da laringe. É um teste de eficiência glótica por excelência (BEHLAU, 2001). BEHLAU \& PONTES, 1995, encontraram em falantes da cidade de São Paulo, valores em torno de 20 segundos para homens e 14 segundos para mulheres. Valores menores que 10 segundos devem ser considerados não-normais com alta significância.

YANAGIHARA \& VON LEDEN (1967) afirmam que o tempo máximo de fonação é alcançado por três fatores fisiológicos: capacidade do ar total disponível para a produção da voz, força expiratória e ajuste da laringe para o uso eficiente do ar, isto é, resistência glótica.

HIRANO, KOIKE e VON LEDEN (1968) avaliaram 25 indivíduos de cada gênero e definiram que valores de tempo máximo de fonação inferiores a10s são considerados patológicos. Sugerem, ainda, que este fato se deve ao controle glótico ou funcionamento respiratório ineficiente. 
COOPER (1974) cita a ocorrência de alterações respiratórias em 86\% das parafonias funcionais e $89 \%$ nas disfonias orgânicas, torácica superior ou clavicular.

A obesidade mórbida, como já é sabido, é de alta prevalência no mundo ocidental e as suas conseqüências biopsicosociais constituem verdadeiro problema de saúde pública.

É considerada uma doença crônica e grave e seu crescimento é alarmante em todo o mundo, com prevalência estimada, de quase $40 \%$ na população norte-americana e $20 \%$ na população brasileira no período de 1989 a 1994 (ANTIPATIS e GILL, 2001).

A sua etiologia é complexa e as alterações fisiopatológicas associadas à obesidade, comprometem virtualmente todos os sistemas do organismo (MANCINI, 2001).

Uma dessas alterações é a disposição corporal de tecido adiposo excessivo. Os indivíduos obesos apresentam deposição anormal de gordura na úvula, palato mole, paredes laterais e posterior da faringe, e região posterior de língua, estruturas estas pertencentes à composição do trato vocal (MOURA, 1996). 
MOORE, JUILLARD e WARD (1987) descrevem características fisiológicas dos obesos ressaltando que esses sujeitos possuem pescoço curto e excessiva gordura subcutânea nesta região.

MOURA (1996) comprova, por meio de ressonância magnética, que sujeitos obesos possuem a presença de depósitos gordurosos em face, região molar, tórax, língua, palato, faringe e região posterior e anterior da laringe. Também descreve em seus estudos que, devido ao acúmulo anormal de gordura nas vias aéreas superiores (VAS), existe aumento do espessamento das paredes laterais da faringe, do tamanho da língua e do comprimento da massa do palato mole.

ALOÉ et al. (1997) relatam que, devido à presença desse depósito de tecido adiposo em região rinofaringe, orofaringe e laringe, existem uma modificação de estreitamento geométrico das Vias Aéreas Superiores traquéia extratorácica, faringe, laringe e nariz. Essa alteração provoca redução no funcionamento e na sensibilidade de quimio-receptores respiratórios, o que será compensado por hiperatividade da musculatura dilatadora faríngea.

Neste contexto observa-se que os pacientes portadores de Obesidade Mórbida podem apresentar alterações. Alterações da voz podem representar uma destas afecções conseqüentes, onde eventualmente, os métodos terapêuticos possam interferir. Para tanto, é importante, sem 
dúvida, caracterizar inicialmente a voz destes indivíduos. Esse foi o princípio que nos levou ao desenvolvimento deste estudo.

BORTOLOTTI \& ANDRADA E SILVA, 2005, realizaram estudo com 21 mulheres portadoras de obesidade mórbida por meio da avaliação dinâmica respiratória, do sistema sensório motor oral, da análise perceptivoauditiva e acústica da voz. Os resultados mostraram uma capacidade respiratória vital reduzida, alterações dos órgãos fonoarticulatórios, qualidade vocal predominantemente rouca-soprosa com presença de incoordenação pneumofônica e freqüência fundamental grave para o padrão feminino.

DALLACQUA, 2004, em estudo com pacientes portadores de obesidade mórbida, notou que pessoas submetidas à cirurgia de gastroplastia redutora alcançam um emagrecimento acentuado e acabam tendo mudanças em sua voz. Foi realizada análise acústica da voz antes e depois do tratamento cirúrgico para a obesidade. Refere que o indivíduo submetido a essa cirurgia deve se preparar tanto para a perda de peso quanto para alterações em sua qualidade vocal, uma vez que mudanças na voz têm importância psicológica na auto-imagem de cada indivíduo.

Algumas explicações podem justificar tal mudança na qualidade vocal com o aumento de peso. Todas se baseiam em estudos que correlacionam obesidade e fatores que são potencialmente moduladores e modificadores 
da voz. Destacam-se o Refluxo Gastroesofágico (e o Refluxo Faringolaríngeo), o ronco (e a Síndrome da Apnéia-Hipopnéia Obstrutiva do sono) e a asma (DI FRANCESCO et al., 2004; FUJITA et al., 2002; MANCINI, 2001; AKERMAN, 2004).

DI FRANCESCO et al., em 2004, realizaram estudo em que se observou que o Refluxo Gastroesofágico (RGE) foi significativamente mais freqüente em pacientes obesos do que no grupo controle. Os autores afirmam neste estudo que o RGE está associado à obesidade.

Em estudo realizado por PELLEGRINI e MARZOCCA, 2002, a prevalência de sintomas esofagianos em pacientes obesos foi de $45 \%$ versus $15 \%$ no grupo controle.

GOMES ESCUDERO et al., 2002, referem que o esfíncter esofágico inferior hipotônico, mobilidade esofágica inefetiva e presença de hérnia hiatal são mecanismos da fisiopatologia propostos como indutores do RGE em pacientes obesos.

Os sinais laríngeos sugestivos de lesão por RGE, são um fator de irritação crônico, o qual interfere na vibração adequada das pregas vocais, levando a uma irregularidade dos movimentos muco-ondulatórios onde muitas vezes o indivíduo permanece com uma alteração leve de voz. 
KOUFMAN, 1995, refere que os achados laringológicos encontrados em pacientes com RGE são: edema laríngeo, eritema de laringite posterior (aritenóides avermelhadas, hipertrofia e irritação na comissura posterior). Estes achados porém não estão presentes em todos os pacientes com RGE, na experiência do autor, sendo o edema o principal e mais comum achado laríngeo do RGE.

SATALOFF et al., 1997, relatam que existe uma grande importância nas diferentes fases verticais da onda mucosa. Esta complexidade é necessária para a fonação normal. Qualquer coisa que interfira, pode resultar em disfunção da voz. Conseqüentemente, deve estar claro que a irritação da prega vocal pelo refluxo gastroesofágico é capaz não somente de produzir lesão, sintomas irritativos (queimação e inchaço da garganta), mas, além disso, interferir na fonação por causa do edema da margem vibratória e na lâmina própria da prega vocal, o que realmente altera a voz.

TOOHILL \& KUHN (1997), ROSS et al. (1998) enfatizam muito a importância do RGE no determinismo das alterações vocais não se preocupando ou deixando de lado a análise destas alterações em função de outras mudanças físicas da própria obesidade excessiva.

O ronco por sua vez é causado pela vibração de tecidos moles em áreas estenóticas das Vias Aéreas Superiores, que possuem um esqueleto ósseo coberto por estruturas complacentes (FUJITA et al., 2002). Como 
fatores associados têm a obesidade, hipertensão arterial e RGE. A obesidade é um fator predisponente, particularmente pela adiposidade na parte superior do corpo, com aumento de tecido mole da faringe ou de tecido linfóide.

BITTENCOURT, 2002, refere que é sabido que o aumento do peso se correlaciona com a gravidade e a freqüência da apnéia e da hipoxemia. Assim, a perda de peso suficiente pode melhorar a apnéia do sono e, portanto, deve ser sempre tentada. Poucos estudos entretanto têm-se preocupado em avaliar sistematicamente os efeitos da perda de peso em pacientes portadores de obesidade e a Síndrome da Apnéia e Hipopnéia Obstrutiva do Sono (SAHOS).

SIMARD et al., em 2004, referem que asma e a Síndrome da apnéia do sono são freqüentes em pacientes portadores de obesidade mórbida.

Em estudo realizado por AKERMAN et al., 2004, notou-se que a associação da asma com obesidade sugere que a obesidade pode ser um potencial de risco para a asma.

Partindo da idéia de que a voz é modificada pelo trato vocal, ou seja, pela faringe, boca e nariz, supomos que no indivíduo obeso deve haver modificação destas estruturas, levando a mudança na voz decorrente do aumento de peso. 
Nota-se desta revisão da literatura que existem evidências quanto as alterações da voz em pacientes portadores de Obesidade Mórbida. Também ressalta-se a grande discussão em torno do tema quanto às causas envolvidas. Embora exista esta preocupação, não são encontrados dados precisos que caracterizem a voz destes pacientes como padrão conseqüente à obesidade, nem evidências de que estas alterações sejam próprias da obesidade. Desta forma é pertinente estudar-se o padrão de voz do paciente portador de Obesidade Mórbida para definir e caracterizar este padrão. 


\section{OBJETIVO}

O objetivo deste estudo é caracterizar a voz dos indivíduos portadores de obesidade mórbida, através das análises dos parâmetros vocais comparado-a aos de indivíduos não obesos, através da análise perceptivoauditiva e acústica. 


\section{CASUÍSTICA E MÉTODOS}

\subsection{CASUÍSTICA}

Foi realizado estudo prospectivo, pareado no qual foram selecionados 45 indivíduos adultos voluntários, provenientes do Ambulatório de Obesidade da Disciplina de Cirurgia do Aparelho Digestivo, de ambos os sexos com IMC acima de $35 \mathrm{Kg} / \mathrm{m}^{2}$, constituindo o grupo em estudo (GO). Para cada indivíduo do grupo em estudo, foi selecionado também um indivíduo adulto voluntário, proveniente do local de trabalho da pesquisadora, pareado por sexo, idade ( \pm 1 ano) e tabagismo, porém com IMC abaixo de $30 \mathrm{Kg} / \mathrm{m}^{2}$, os quais constituíram o grupo controle (GC). Dados demográficos referentes aos 90 indivíduos estudados estão expressos na TABELA 1.

TABELA 1: Dados demográficos dos indivíduos estudados.

\begin{tabular}{|c|c|c|c|}
\hline & \multicolumn{2}{c}{ Grupo } \\
\cline { 2 - 4 } & $\begin{array}{c}\text { Obeso } \\
(\mathrm{n}=45)\end{array}$ & $\begin{array}{c}\text { Controle } \\
(\mathrm{n}=45)\end{array}$ & \\
\hline Sexo & $14(31,1 \%)$ & $14(31,1 \%)$ & 1,0 \\
Masculino & $31(69,9 \%)$ & $31(69,9 \%)$ & 0,86 \\
Feminino & $43,3 \pm 12,0$ & $43,4 \pm 12,0$ & \\
\hline Idade (anos) & $41(91,1 \%)$ & $41(91,1 \%)$ & 1,0 \\
\hline Tabagismo & & & \\
\hline Não & & & \\
\hline
\end{tabular}




\begin{tabular}{|c|c|c|c|}
\hline $\begin{array}{c}30 \mathrm{cig} / \mathrm{dia} \\
\geq 10 \mathrm{cig} / \mathrm{dia}\end{array}$ & $\begin{array}{c}3(6,7 \%) \\
1(2,2 \%)\end{array}$ & $1(2,2 \%)$ & \\
\hline Peso $(\mathrm{Kg})$ & $131,4 \pm 25,6$ & $68,7 \pm 12,3$ & $<0,001$ \\
\hline Altura $(\mathrm{m})$ & $1,65 \pm 0,11$ & $1,66 \pm 0,09$ & 0,54 \\
\hline IMC $\left(\mathrm{Kg} / \mathrm{m}^{2}\right)$ & $48,3 \pm 6,4$ & $24,9 \pm 3,4$ & \\
$<20$ & $0(0,0 \%)$ & $3(6,7 \%)$ & \\
$20-24,9$ & $0(0,0 \%)$ & $20(44,4 \%)$ & \\
$25-29,9$ & $0(0,0 \%)$ & $22(48,9 \%)$ & $<0,001$ \\
$30-34,9$ & $0(0,0 \%)$ & $0(0,0 \%)$ & \\
$35-39,9$ & $5(11,1 \%)$ & $0(0,0 \%)$ & \\
$\geq 40$ & $40(88,9 \%)$ & $0(0,0 \%)$ & \\
\hline
\end{tabular}

Dados apresentados como média \pm desvio padrão ou n (\%)

Todos os indivíduos envolvidos responderam a um questionário (ANEXO1) e assinaram consentimento informado pós-esclarecido (ANEXO 2). O projeto de pesquisa foi aprovado na Comissão de Ética do HCFMUSP sob protocolo de pesquisa número 1283/05 (ANEXO 3).

Os critérios de exclusão para entrada no estudo foram diagnósticos de lesões neoplásicas malignas em cabeça e pescoço, cirurgias prévias da região orofaríngea ou alterações de vias aéreas superiores (gripe, rinite, sinusite, faringite, amigdalite). 


\subsection{MÉTODOS}

Todos os indivíduos foram submetidos a exame vídeo-estrobolaringoscópico no Ambulatório de Otorrinolaringologia do HCFMUSP (FIGURA 1 e ANEXO 6) e à gravação da voz no Setor de Fonoaudiologia do Ambulatório de Otorrinolaringologia. Os exames foram realizados sempre pelo mesmo médico, gravados em DVD e os diagnósticos foram feitos por dois médicos diferentes, especialistas em Laringologia e Voz do HCFMUSP, por unanimidade. A avaliação da voz foi realizada de maneira examinador "cego", ou seja, o examinador desconhecia a que grupo o indivíduo pertencia.

Após a realização do exame de laringe os indivíduos realizaram a gravação da voz, a qual foi realizada pela pesquisadora.

\section{Técnica de Exame}

Exame de Laringe:

Foi pedido aos indivíduos que abrissem a boca e emitissem a vogal /e/ prolongada para realização do exame laringológico. 


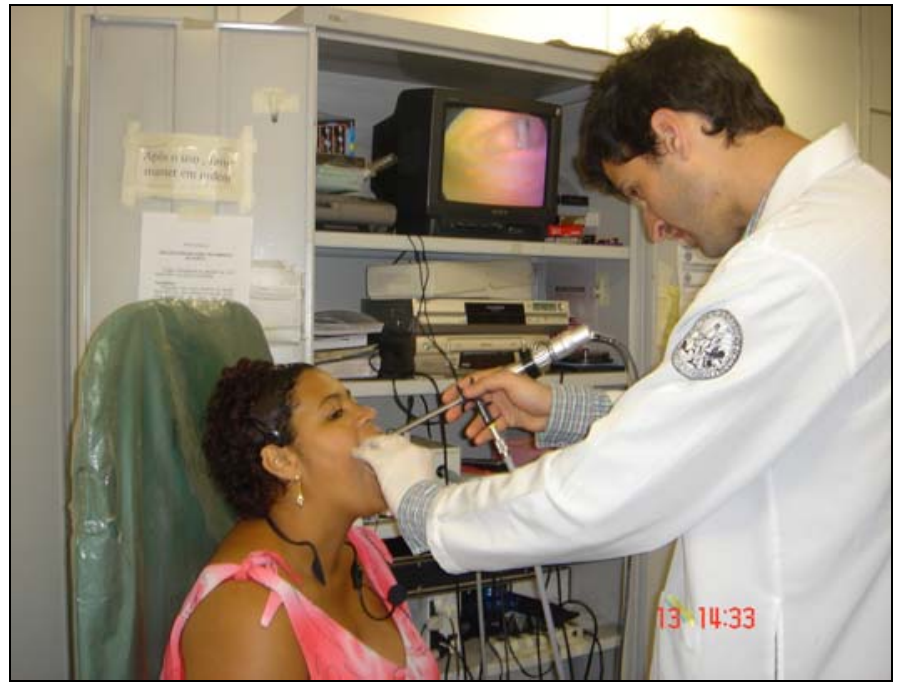

Figura 1 - Médico Laringologista realizando exame vídeo-estrobo-laringoscópico.

Após a avaliação pelos médicos laringologistas, os exames de laringe foram categorizados como normais (sem lesões de pregas vocais) ou alterados (com lesões de pregas vocais). De acordo com os critérios de KOUFMAN (1995), os indivíduos foram considerados com tendo sinais laríngeos sugestivos de lesão por Refluxo Gastro-esofágico quando apresentavam paquidermia, hiperemia e/ou edema interaritenoideo; e/ou pseudo-sulco nas pregas vocais.

Gravação da Voz:

Foi pedido aos indivíduos que emitissem as vogais $/ a / \mathrm{e} / \varepsilon /$, prolongadas, de maneira natural e confortável, em intensidade e altura habituais, sem tentar impostar a voz, e que contassem os números de 1 a 20. Todas essas emissões foram gravadas em um computador Pentium II e 
microfone headset unidirecional da marca "Plantronics", colocado a uma distância de três centímetros da boca de cada indivíduo, em uma cabina com isolamento acústico (FIGURA 2).

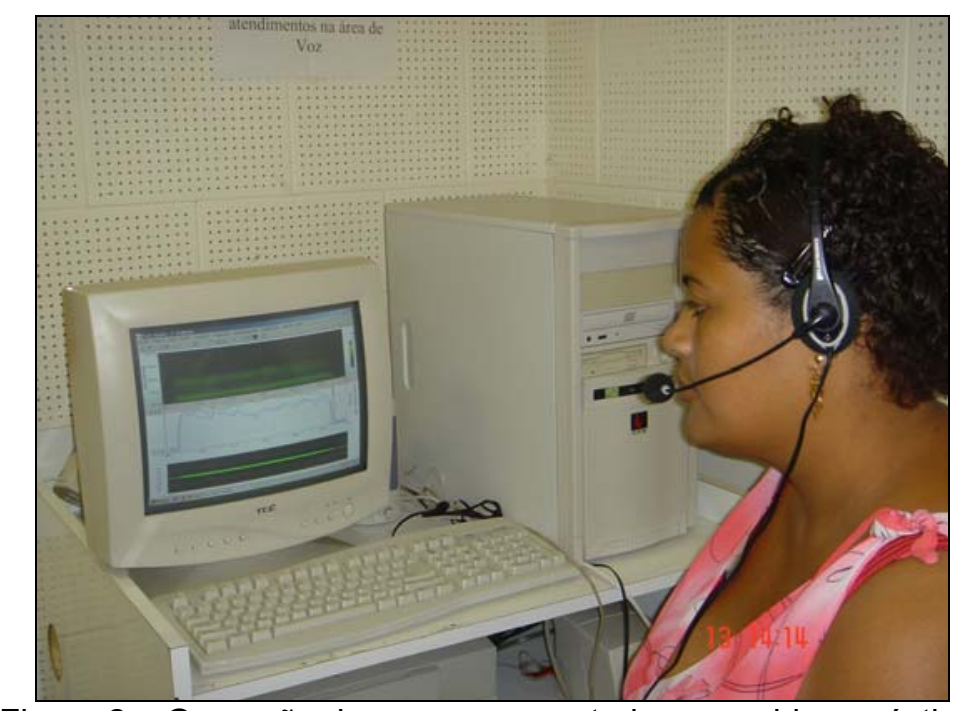

Figura 2 - Gravação da voz no computador em cabina acústica.

Os indivíduos foram submetidos à avaliação subjetiva perceptivoauditiva da qualidade vocal, através da escala GRBAS (HIRANO, 1981), acrescentado de instabilidade (I - Instability) (DEJONCKERE, REMACLE \& FRESNEL-ELBAZE, 1996). Foram avaliadas também estrangulamento ou fry no final das emissões - encurtamento máximo das pregas vocais. A gradação de desvio da escala GIRBAS é de Zero (sem desvio) a 3 (desvio severo) (ANEXO 5). Quanto ao estrangulamento ou "vocal fry" foi categorizada como presença ou ausência.

Foi avaliada também a ressonância da produção vocal de cada indivíduo, tendo sido categorizada como equilibrada ou não-equilibrada 
(quando fosse categorizada como laringo-faríngea, faríngea, hipernasal ou hiponasal) conforme BEHLAU, 2001.

A determinação da escala GIRBAS, e de todos os outros parâmetros da análise perceptivo-auditiva das vozes gravadas, foram realizadas em uma mesma ocasião por três fonoaudiólogas especialistas em voz com experiência na área por no mínimo cinco anos, as quais não tinham conhecimento quanto a qual grupo o indivíduo pertencia.

Quando havia discordância entre as avaliações das três fonoaudiólogas, o caso era reavaliado até que se chegasse a consenso.

A análise acústica foi realizada objetivamente através do mesmo computador utilizando os softwares VOX METRIA versão 4.0.47 e PRAAT.

Estes softwares forneceram para cada indivíduo os valores numéricos de Freqüência Fundamental (Fo), “Jitter”, "Shimmer”, Ruído e Tempo Máximo Fonatório (ANEXO 4).

Os valores de referência utilizados para freqüência fundamental foi a média de $113 \mathrm{~Hz}$ e $205 \mathrm{~Hz}$ para homens e mulheres, respectivamente (BEHLAU, 1984; BEHLAU, TOSI E PONTES, 1985). 
Para análise do "jitter" o software (VOXMETRIA) utilizado neste estudo tinha o valor de normalidade de $0,6 \%$. Os indivíduos com valores acima de $0,6 \%$ foram considerados com "jitter" alterado.

Para análise do "shimmer" o software (VOXMETRIA) utilizado neste estudo tinha o valor de normalidade de $6,5 \%$. Os indivíduos com valores acima de $6,5 \%$ foram considerados com "shimmer" alterado.

Para análise do ruído o software (VOXMETRIA) utilizado neste estudo tinha o valor de normalidade de 2,5. Os indivíduos com valores acima de 2,5 foram considerados com ruído alterado.

Foram considerados como valores de referência de tempo máximo fonatório os valores em torno de 20 segundos para homens e 14 segundos para mulheres, conforme o estudo realizado por BEHLAU \& PONTES, 1995, onde encontraram em falantes da cidade de São Paulo. Valores menores que 10 segundos foram considerados não-normais com alta significância.

Todos estes parâmetros foram estudados globalmente comparandose o GO com GC e também entre o GO sem lesões laríngeas e seu correspondente no GC. Uma vez que as lesões laríngeas poderiam alterar os dados das análises perceptivo-auditiva e acústica das vozes dos indivíduos estudados, optamos por realizar novamente a análise, excluindo- 
se os 16 pares obeso-controle que apresentavam lesões laríngeas para que a presença das mesmas não interferisse nos resultados.

\section{Análise Estatística}

As médias de Fo e tempo máximo fonatório foram comparadas entre os grupos através do teste não paramétrico de Wilcoxon. As proporções de alteração nos valores de "jitter", "shimmer" e Ruído, bem como as proporções entre a categoria de ressonância "vocal fry", e estrangulamento foram comparadas entre os grupos utilizando-se o teste do Qui-quadrado e o Teste exato de Fisher. As proporções dos escores de cada item da qualidade vocal (GIRBAS) foram comparadas entre os grupos através do teste do qui-quadrado.

Valores de $p$ menores que 0,05 foram considerados estatisticamente significantes. Os dados foram analisados com o software Statistical Package for Social Sciences (SPSS ${ }^{\circledR}$ for Windows 10.0, SPSS Inc., Chicago, IL). 


\section{RESULTADOS}

Os achados à laringoscopia em ambos os grupos estão apresentados na TABELA 2.

TABELA 2: Achados Laringoscópicos.

\begin{tabular}{|c|c|c|c|}
\hline & \multicolumn{2}{|c|}{ Grupo } & \multirow[b]{2}{*}{$p$} \\
\hline & $\begin{array}{l}\text { Obeso } \\
(n=45)\end{array}$ & $\begin{array}{l}\text { Controle } \\
(n=45)\end{array}$ & \\
\hline \multicolumn{4}{|l|}{ Laringoscopia } \\
\hline Normal & $33(73,3 \%)$ & $39(86,7 \%)$ & 0,11 \\
\hline Alterada & $12(26,7 \%)$ & $6(13,3 \%)$ & \\
\hline Cisto de PV & 2 & 1 & \\
\hline AEM não especificada & 1 & 0 & \\
\hline Vasculodisgenesia & 3 & 1 & \\
\hline Cordite & 2 & 0 & \\
\hline Espessamento Nodular & 2 & 1 & \\
\hline Granuloma de processo vocal & 1 & 1 & \\
\hline $\begin{array}{l}\text { Hipertrofia de banda } \\
\text { ventricular }\end{array}$ & 1 & 0 & \\
\hline Úlceras de Pênfigo Vulgar & 1 & 0 & \\
\hline Sulco de PV & 1 & 0 & \\
\hline Pólipo de PV & 0 & 1 & \\
\hline Edema de Reinke & 0 & 1 & \\
\hline $\begin{array}{l}\text { Sinais laríngeos sugestivos de } \\
\text { lesão por RGE }\end{array}$ & $19(42,2 \%)$ & $10(22,2 \%)$ & $<0,042$ \\
\hline
\end{tabular}

${ }^{*}$ Alguns indivíduos apresentavam mais de uma lesão associada

RGE = Refluxo Gastro-Esofágico 
Os resultados da análise perceptivo-auditiva (GIRBAS) estão apresentados na TABELA 3 e representados graficamente nas FIGURAS 3, $4,5,6,7$ e 8 .

TABELA 3: Prevalências dos graus $0,1,2$ e 3 de GIRBAS entre os grupos obeso e controle.

\begin{tabular}{|c|c|c|c|c|c|c|c|c|c|}
\hline \multicolumn{10}{|c|}{ Grupo } \\
\hline & \multicolumn{4}{|c|}{$\begin{array}{l}\text { Obeso } \\
(n=45)\end{array}$} & \multicolumn{4}{|c|}{$\begin{array}{c}\text { Controle } \\
(n=45)\end{array}$} & \multirow[t]{2}{*}{$P$} \\
\hline & 0 & 1 & 2 & 3 & 0 & 1 & 2 & 3 & \\
\hline G & $\begin{array}{c}15 \\
(33,3 \%)\end{array}$ & $\begin{array}{c}28 \\
(62,2 \%)\end{array}$ & $\begin{array}{c}2 \\
(4,4 \%)\end{array}$ & $\begin{array}{c}0 \\
(0,0 \%)\end{array}$ & $\begin{array}{c}33 \\
(73,3 \%)\end{array}$ & $\begin{array}{c}12 \\
(26,7 \%)\end{array}$ & $\begin{array}{c}0 \\
(0,0 \%)\end{array}$ & $\begin{array}{c}0 \\
(0,0 \%)\end{array}$ & 0,001 \\
\hline I & $\begin{array}{c}25 \\
(55,6 \%)\end{array}$ & $\begin{array}{c}19 \\
(42,2 \%)\end{array}$ & $\begin{array}{c}1 \\
(2,2 \%)\end{array}$ & $\begin{array}{c}0 \\
(0,0 \%)\end{array}$ & $\begin{array}{c}41 \\
(91,1 \%)\end{array}$ & $\begin{array}{c}4 \\
(8,9 \%)\end{array}$ & $\begin{array}{c}0 \\
(0,0 \%)\end{array}$ & $\begin{array}{c}0 \\
(0,0 \%)\end{array}$ & 0,001 \\
\hline $\mathbf{R}$ & $\begin{array}{c}17 \\
(37,8 \%)\end{array}$ & $\begin{array}{c}26 \\
(57,8 \%)\end{array}$ & $\begin{array}{c}2 \\
(4,4 \%)\end{array}$ & $\begin{array}{c}0 \\
(0,0 \%)\end{array}$ & $\begin{array}{c}33 \\
(73,3 \%)\end{array}$ & $\begin{array}{c}12 \\
(26,7 \%)\end{array}$ & $\begin{array}{c}0 \\
(0,0 \%)\end{array}$ & $\begin{array}{c}0 \\
(0,0 \%)\end{array}$ & 0,002 \\
\hline B & $\begin{array}{c}33 \\
(73,3 \%)\end{array}$ & $\begin{array}{c}12 \\
(26,7 \%)\end{array}$ & $\begin{array}{c}0 \\
(0,0 \%)\end{array}$ & $\begin{array}{c}0 \\
(0,0 \%)\end{array}$ & $\begin{array}{c}44 \\
(97,8 \%)\end{array}$ & $\begin{array}{c}1 \\
(2,2 \%)\end{array}$ & $\begin{array}{c}0 \\
(0,0 \%)\end{array}$ & $\begin{array}{c}0 \\
(0,0 \%)\end{array}$ & 0,001 \\
\hline A & $\begin{array}{c}45 \\
(100 \%)\end{array}$ & $\begin{array}{c}0 \\
(0,0 \%)\end{array}$ & $\begin{array}{c}0 \\
(0,0 \%)\end{array}$ & $\begin{array}{c}0 \\
(0,0 \%)\end{array}$ & $\begin{array}{c}45 \\
(100 \%)\end{array}$ & $\begin{array}{c}0 \\
(0,0 \%)\end{array}$ & $\begin{array}{c}0 \\
(0,0 \%)\end{array}$ & $\begin{array}{c}0 \\
(0,0 \%)\end{array}$ & - \\
\hline S & $\begin{array}{c}45 \\
(100 \%)\end{array}$ & $\begin{array}{c}0 \\
(0,0 \%)\end{array}$ & $\begin{array}{c}0 \\
(0,0 \%)\end{array}$ & $\begin{array}{c}0 \\
(0,0 \%)\end{array}$ & $\begin{array}{c}45 \\
(100 \%)\end{array}$ & $\begin{array}{c}0 \\
(0,0 \%)\end{array}$ & $\begin{array}{c}0 \\
(0,0 \%)\end{array}$ & $\begin{array}{c}0 \\
(0,0 \%)\end{array}$ & - \\
\hline
\end{tabular}

Legenda: G (Grau da disfonia); I (Instabilidade); R (Rouquidão); B (Soprosidade); A (Astenia); S (Tensão). 


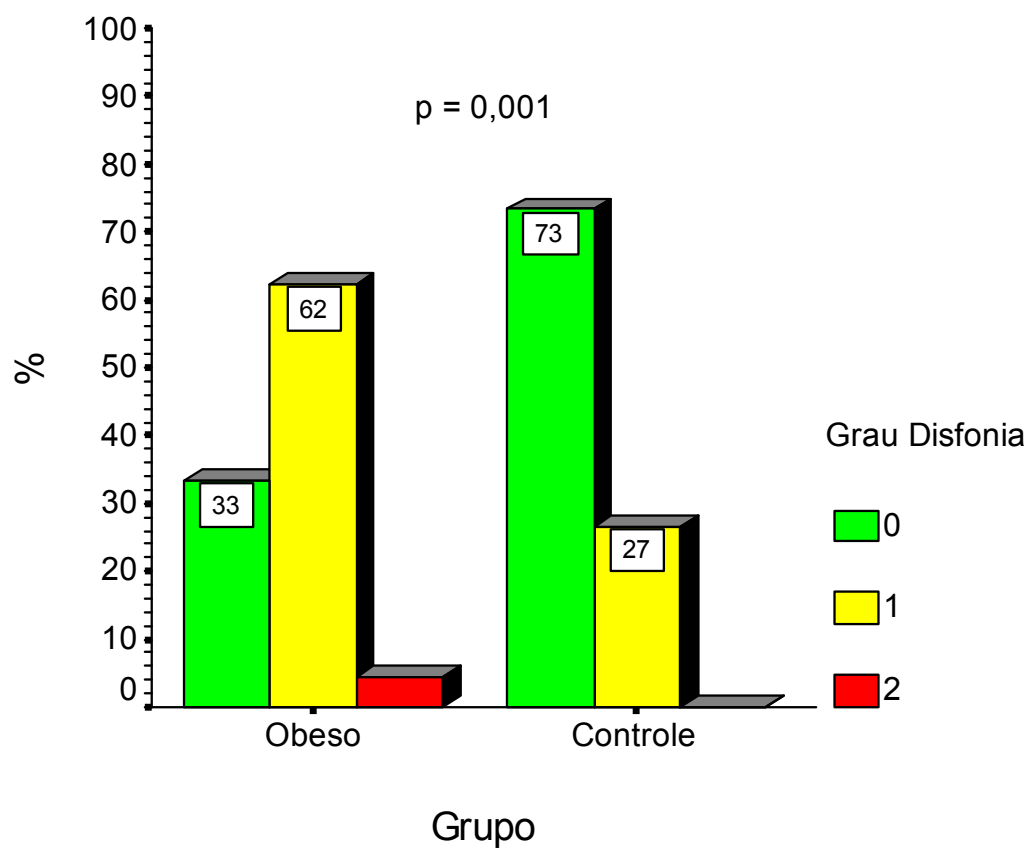

FIGURA 3 - Prevalências dos graus 0, 1 e 2 de disfonia entre os grupos obeso e controle.

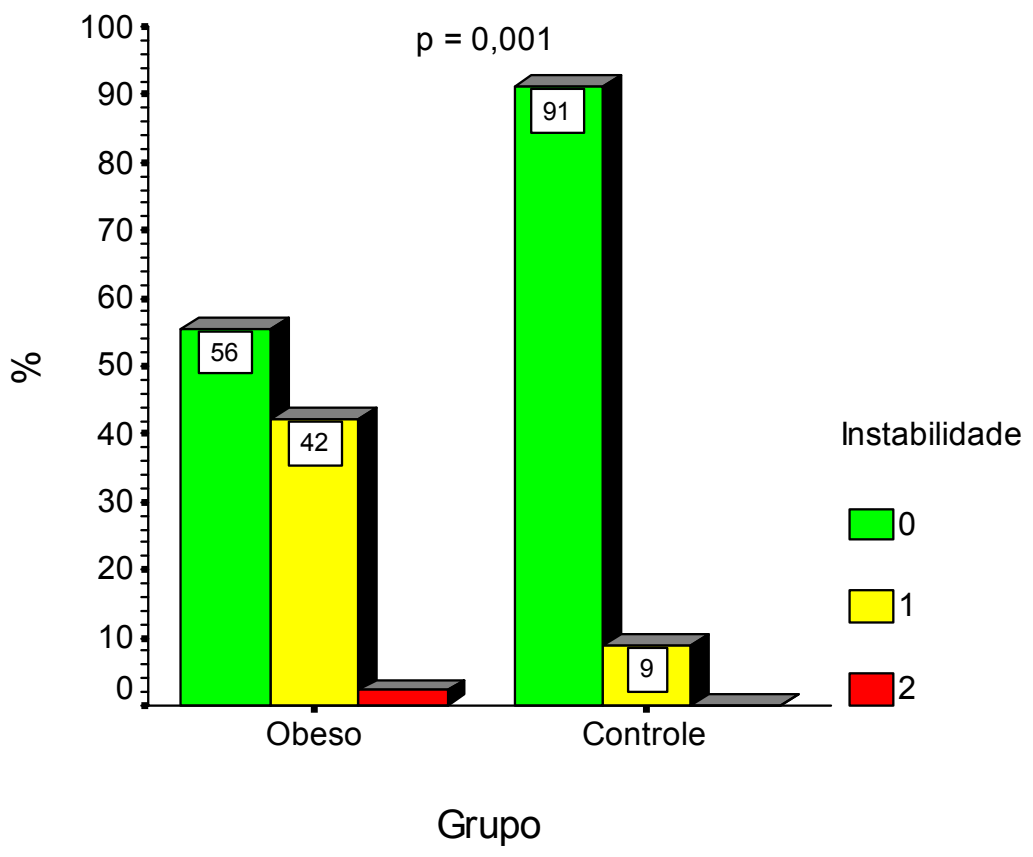

FIGURA 4 - Prevalências dos graus 0,1 e 2 de instabilidade entre os grupos obeso e controle. 


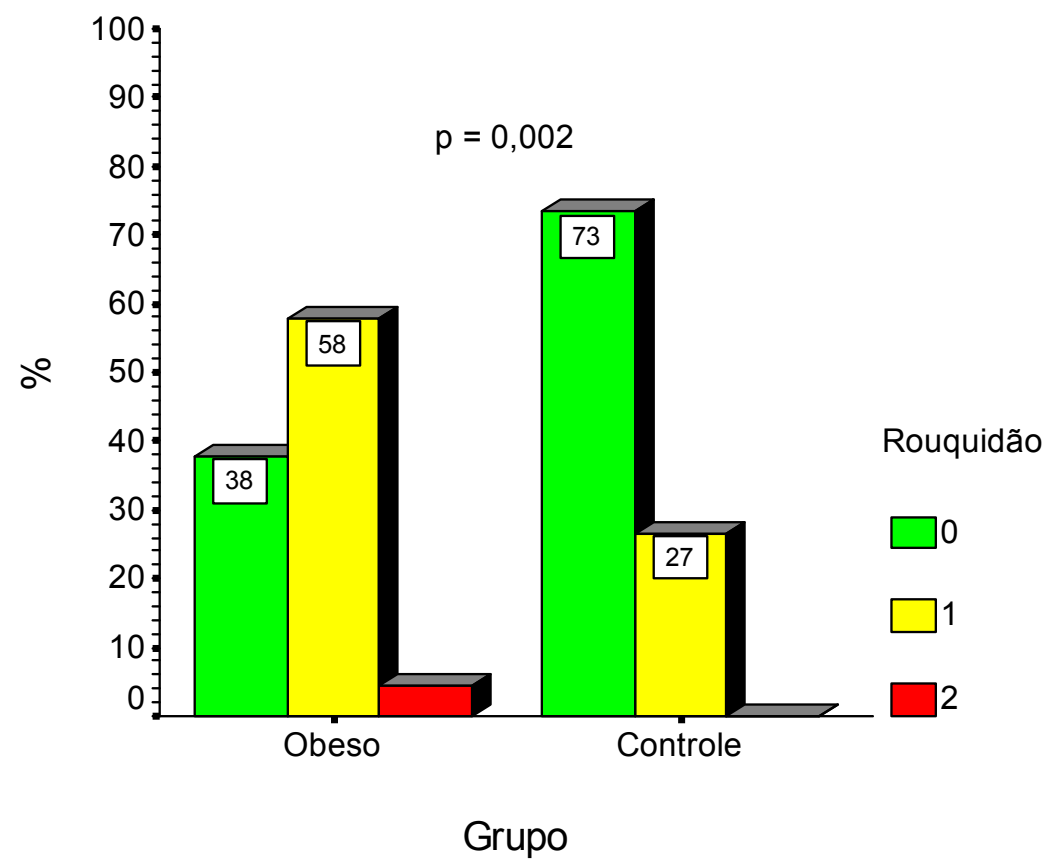

FIGURA 5 - Prevalências dos graus 0,1 e 2 de rouquidão entre os grupos obeso e controle.

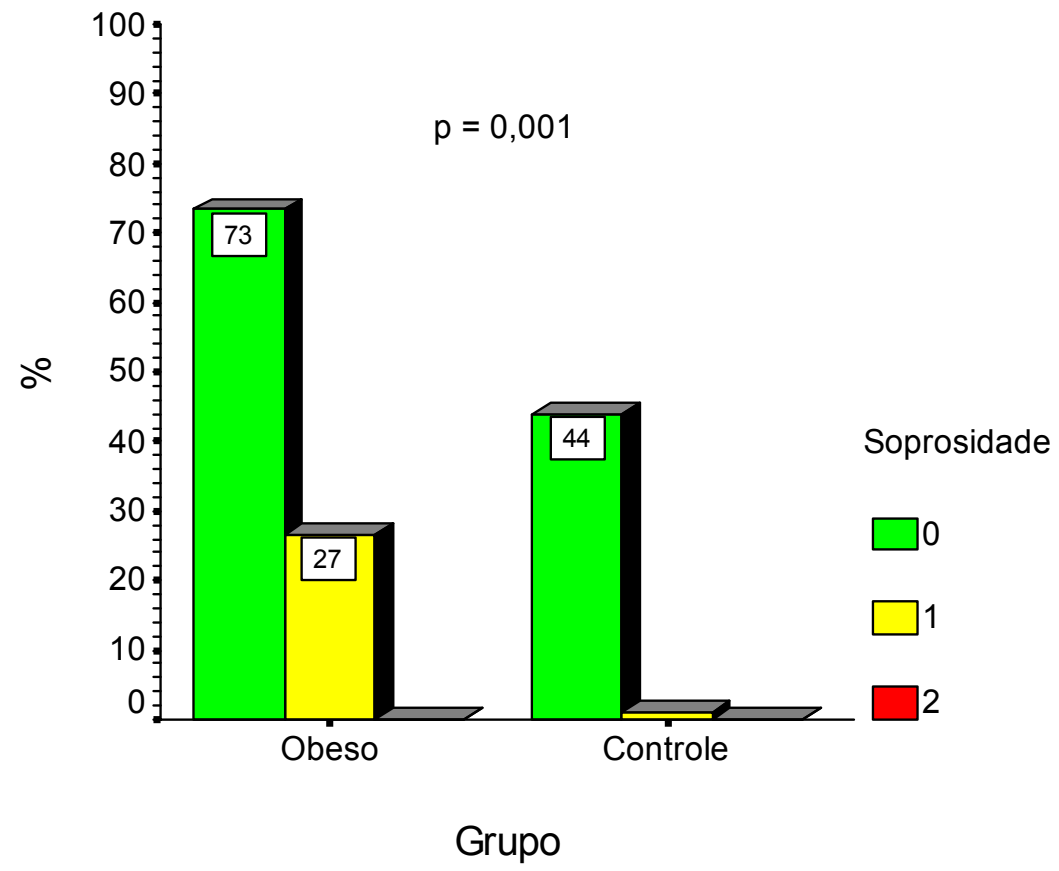

FIGURA 6 - Prevalências dos graus 0, 1 e 2 de soprosidade entre os grupos obeso e controle. 


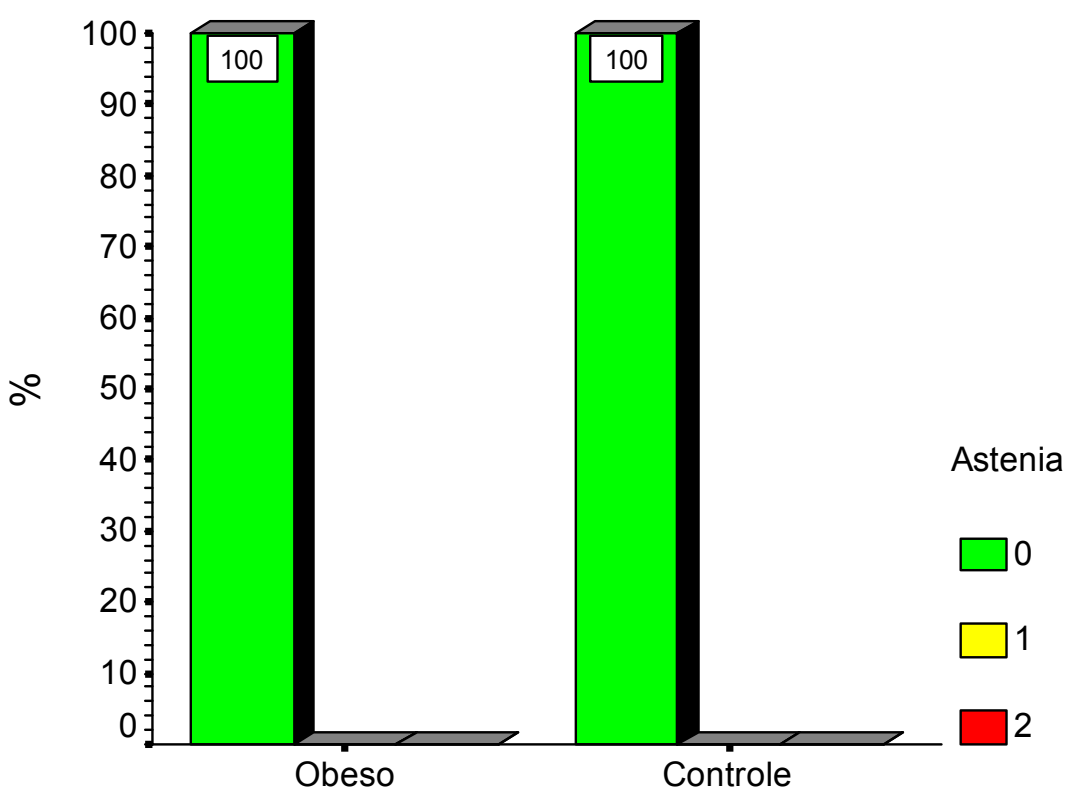

Grupo

FIGURA 7 - Prevalências dos graus 0, 1 e 2 de astenia entre os grupos obeso e controle.

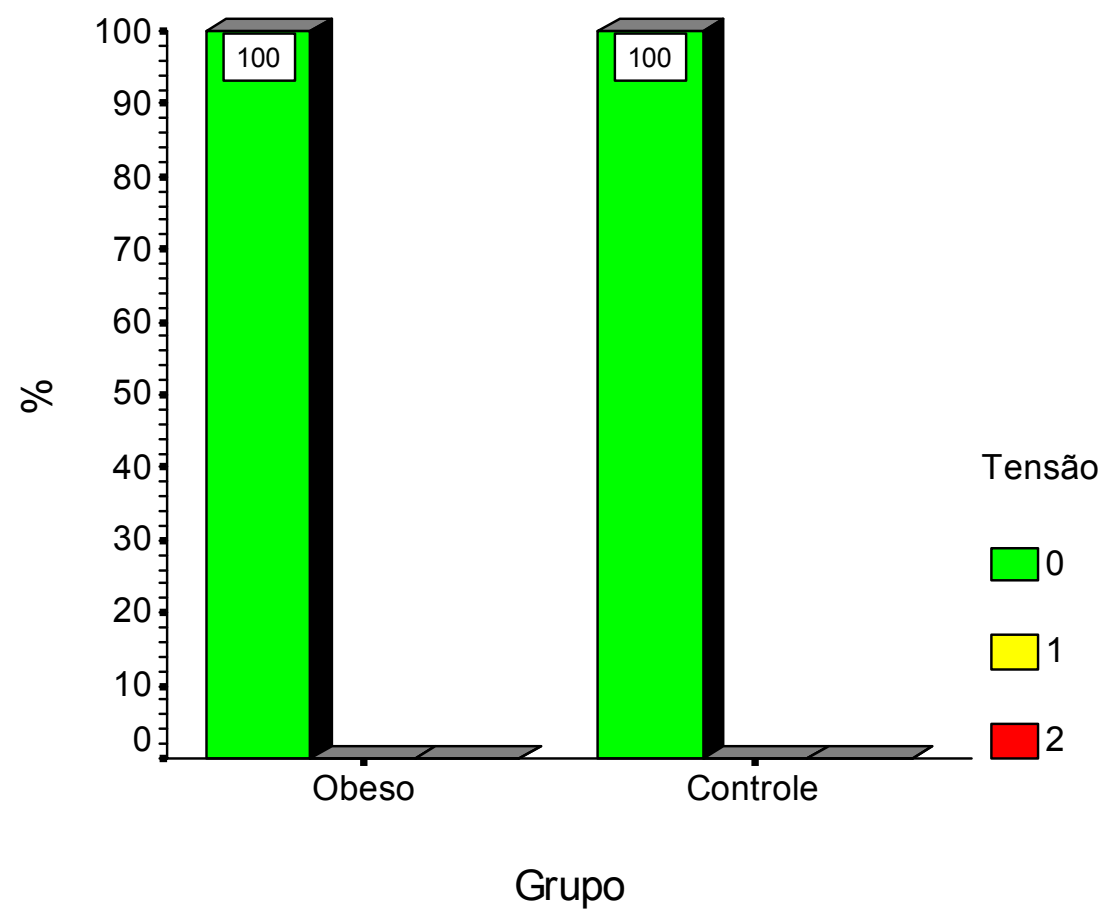

FIGURA 8 - Prevalências dos graus 0, 1 e 2 de tensão entre os grupos obeso e controle. 
Os resultados do "vocal fry" ou estrangulamento ao final das emissões, bem como a ressonância da produção vocal estão apresentados na TABELA 4 e FIGURA 9.

TABELA 4: Prevalência de "Vocal fry", Estrangulamento e Ressonância não equilibrada entre os grupos obeso e controle.

\begin{tabular}{|l|c|c|c|}
\hline & \multicolumn{2}{|c|}{ Grupo } & \\
\hline & $\begin{array}{c}\text { Obeso } \\
(\mathrm{n}=45)\end{array}$ & $\begin{array}{c}\text { Controle } \\
(\mathrm{n}=45)\end{array}$ & $p$ \\
\hline "Vocal fry" & $8(17,8 \%)$ & $5(11,1 \%)$ & 0,37 \\
\hline Estrangulamento & $10(22,2 \%)$ & $0(0,0 \%)$ & 0,001 \\
\hline Ressonância não-equilibrada & $32(71,1 \%)$ & $25(55,6 \%)$ & 0,19 \\
\hline
\end{tabular}

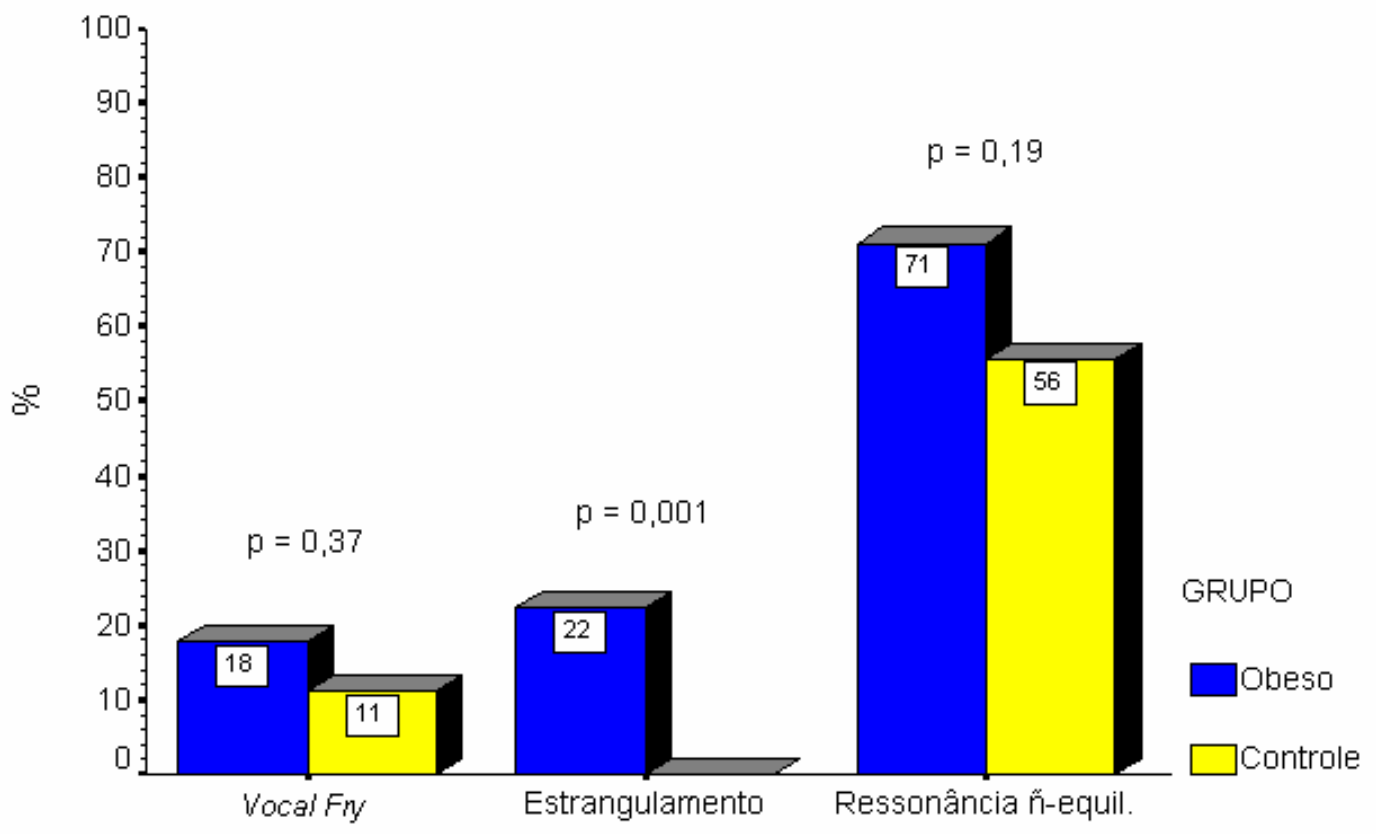

FIGURA 9 - Prevalência de "Vocal fry", Estrangulamento e Ressonância não equilibrada entre os grupos obeso e controle. 
Os resultados da análise acústica (Fo - Freqüência Fundamental, “jitter", "shimmer", Ruído e TMF - Tempo Máximo Fonatório) estão apresentados na TABELA 5 e FIGURAS 10, 11 e 12.

TABELA 5: Prevalências de Freqüência Fundamental, "Jitter", "Shimmer", Ruído e Tempo Máximo fonatório entre os grupos obeso e controle.

\begin{tabular}{|c|c|c|c|}
\hline & \multicolumn{2}{|c|}{ Grupo } & \multirow[b]{2}{*}{$p$} \\
\hline & $\begin{array}{l}\text { Obeso } \\
(n=45)\end{array}$ & $\begin{array}{l}\text { Controle } \\
(n=45)\end{array}$ & \\
\hline $\begin{array}{l}\text { Freqüência Fundamental } \\
(\mathbf{H z}) \\
\quad \text { Homens }(\mathrm{n}=14) \\
\text { Mulheres }(\mathrm{n}=31)\end{array}$ & $\begin{array}{l}135,7(116,8-164,1) \\
192,6(171,6-207,9)\end{array}$ & $\begin{array}{l}119,3(112,0-125,2) \\
203,8(179,4-217,2)\end{array}$ & $\begin{array}{l}0,035 \\
0,068\end{array}$ \\
\hline $\begin{array}{l}\text { “Jitter" } \\
\text { Normal } \\
\text { Alterado }\end{array}$ & $\begin{array}{l}25(55,6 \%) \\
20(44,4 \%)\end{array}$ & $\begin{array}{c}42(93,3 \%) \\
3(6,7 \%)\end{array}$ & $<0,001$ \\
\hline $\begin{array}{c}\text { "Shimmer" } \\
\text { Normal } \\
\text { Alterado }\end{array}$ & $\begin{array}{l}28(62,2 \%) \\
17(37,8 \%)\end{array}$ & $\begin{array}{c}42(93,3 \%) \\
3(6,7 \%)\end{array}$ & $<0,001$ \\
\hline $\begin{array}{l}\text { Ruído } \\
\text { Normal } \\
\text { Alterado }\end{array}$ & $\begin{array}{l}16(35,5 \%) \\
29(64,4 \%)\end{array}$ & $\begin{array}{c}43(95,6 \%) \\
3(6,7 \%)\end{array}$ & $<0,001$ \\
\hline $\begin{array}{l}\text { Tempo máximo fonatório } \\
\text { (seg) } \\
\text { Homens } \\
\text { Mulheres }\end{array}$ & $\begin{array}{l}8,0(5,0-9,3) \\
7,0(5,0-9,0)\end{array}$ & $\begin{array}{l}15,0(10,8-16,3) \\
11,0(13,0-17,0)\end{array}$ & $\begin{array}{r}0,012 \\
<0,001\end{array}$ \\
\hline
\end{tabular}

Dados apresentados como mediana (percentil 25 - 75) ou n (\%) 


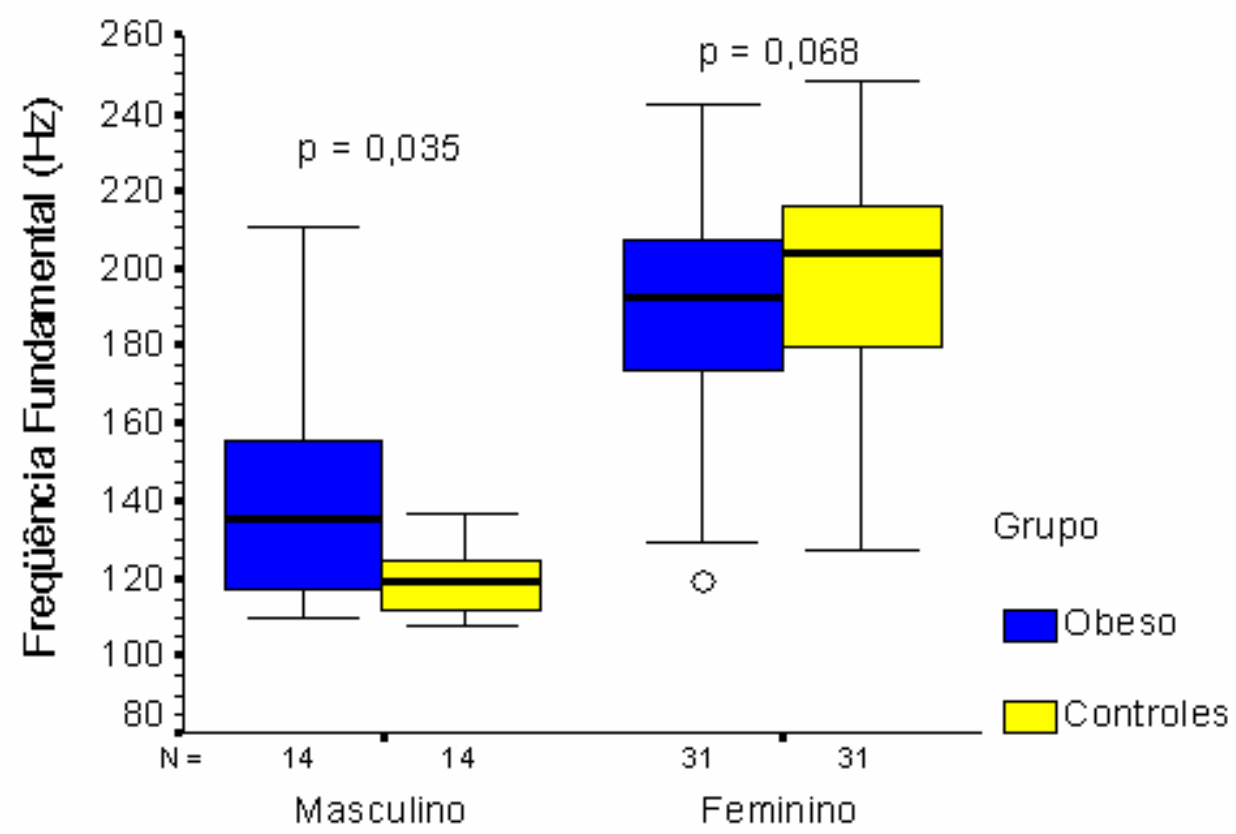

Sexo

FIGURA 10 - Boxplot da Freqüência Fundamental $(\mathrm{Hz})$ entre os grupos obeso e controle agrupados de acordo com o sexo. Cada caixa representa a mediana, quartis e valores extremos dentro de uma categoria. "Outliers" estão representados como círculos ou asteriscos. Valores de $p$ obtidos do teste não paramétrico de Wilcoxon.

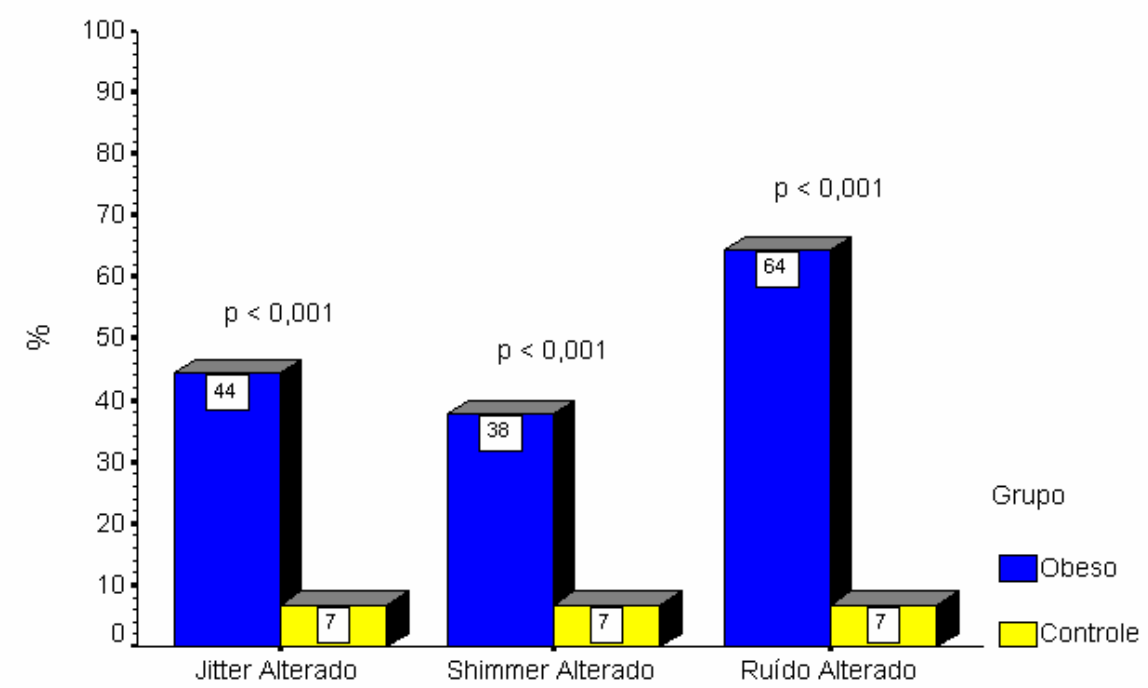

FIGURA 11 - Prevalência de "Jitter", "Shimmer" e Ruído alterados entre os grupos obeso e controle. 


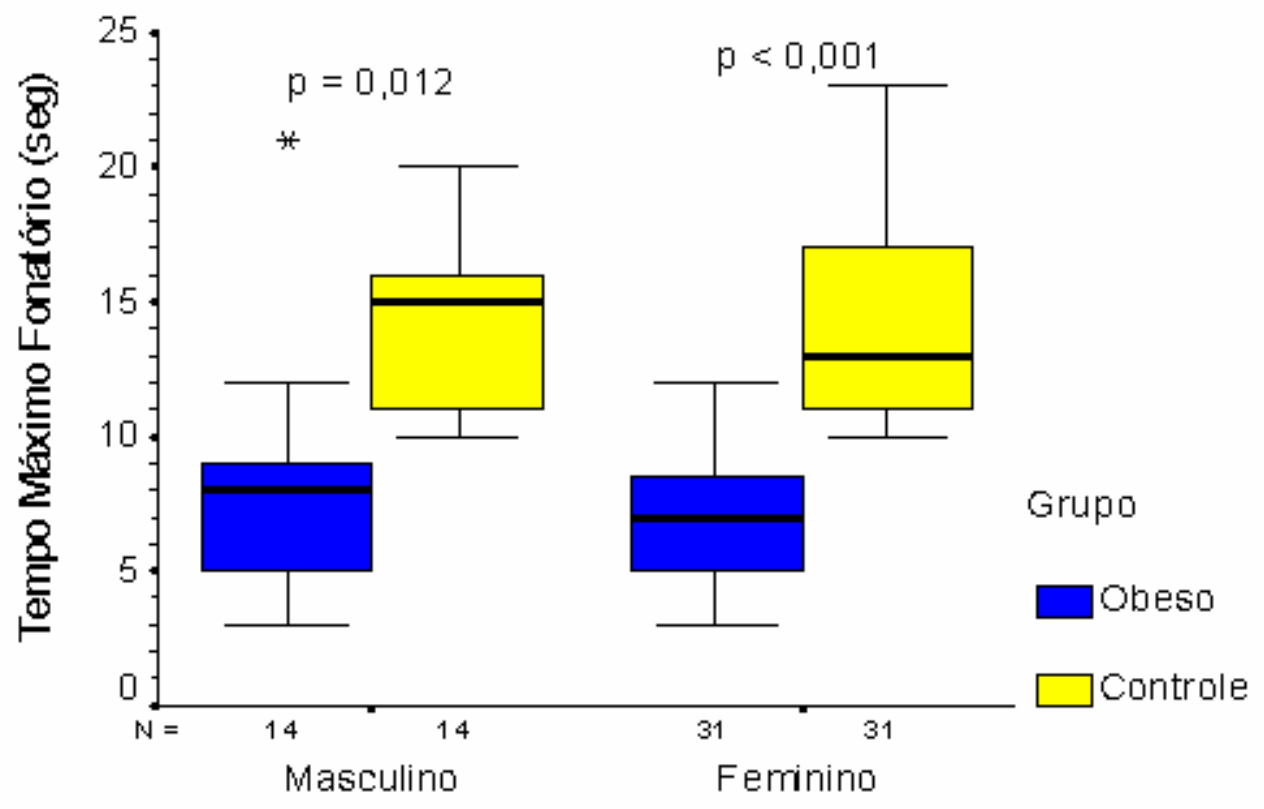

Sexo

FIGURA 12 - Boxplot do Tempo Máximo Fonatório (segundos) entre os grupos obeso e controle agrupados de acordo com o sexo. Cada caixa representa a mediana, quartis e valores extremos dentro de uma categoria. "Outliers" estão representados como círculos ou asteriscos. Valores de $p$ obtidos do teste não paramétrico de Wilcoxon.

Uma vez que as lesões laríngeas poderiam alterar os dados das análises perceptivo-auditiva e acústica das vozes dos indivíduos estudados, optamos por realizar novamente a análise, excluindo-se os 16 pares obesocontrole que apresentavam lesões laríngeas para que a presença das mesmas não interferisse nos resultados.

Na TABELA 6, 7 e FIGURAS 13, 14, 15, 16, 17, 18, 19 e na TABELA 8 e FIGURAS 20, 21, 22, estão apresentados os dados da análise perceptivo-auditiva e acústica respectivamente. 
TABELA 6: Análise perceptivo-auditiva dos indivíduos estudados, após exclusão de 16 pares obeso-controle que apresentavam lesões à laringoscopia.

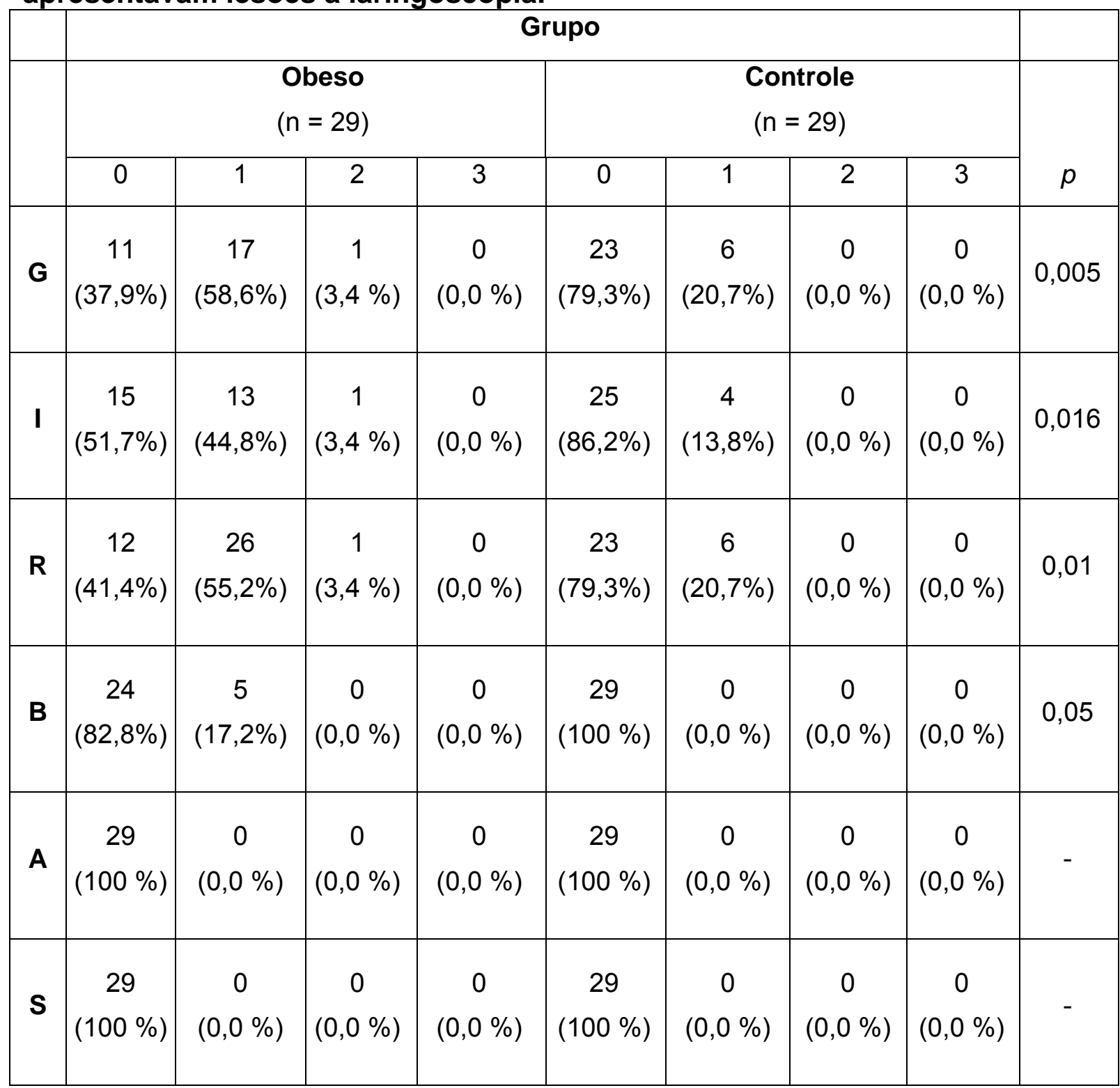

Legenda: G (Grau da disfonia); I (Instabilidade); R (Rouquidão); B (Soprosidade); A (Astenia); S (Tensão). 


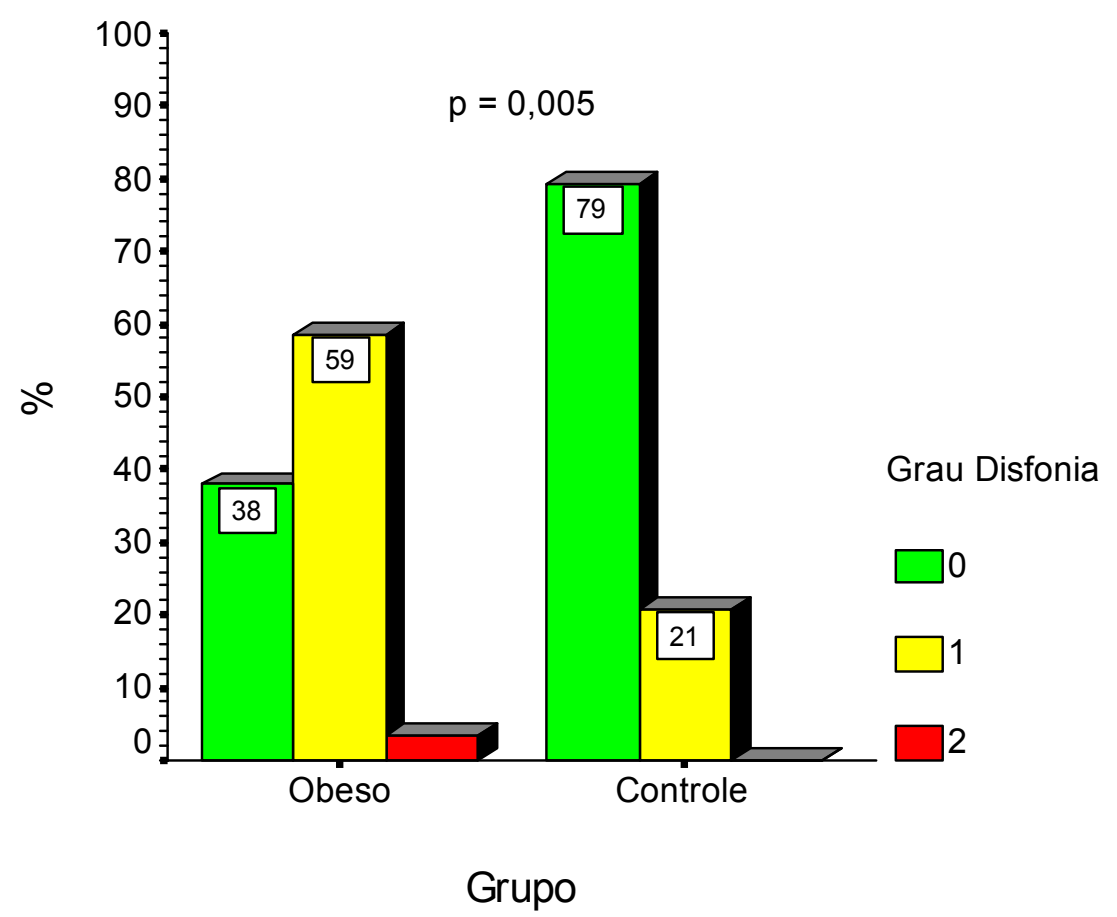

FIGURA 13 - Prevalências dos graus 0, 1 e 2 de disfonia entre os grupos obeso e controle, após exclusão de 16 pares obeso-controle que apresentavam lesões à laringoscopia.

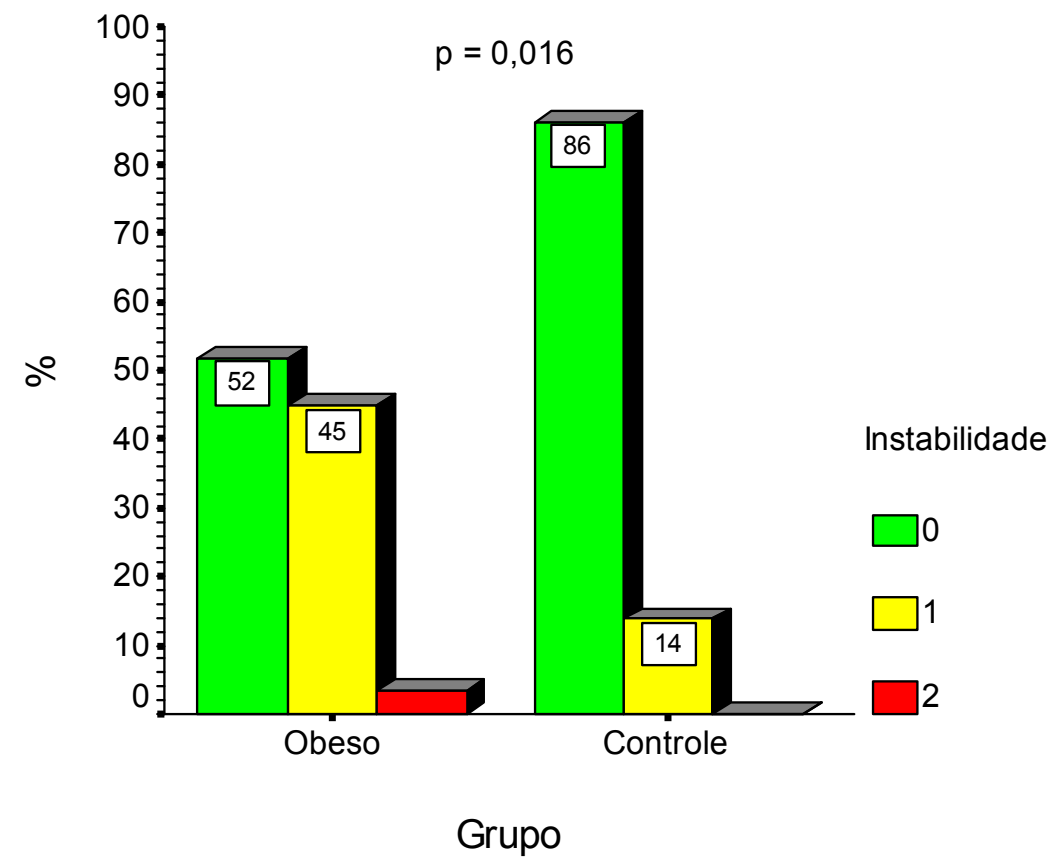

FIGURA 14 - Prevalências dos graus 0, 1 e 2 de instabilidade entre os grupos obeso e controle, após exclusão de 16 pares obeso-controle que apresentavam lesões à laringoscopia. 


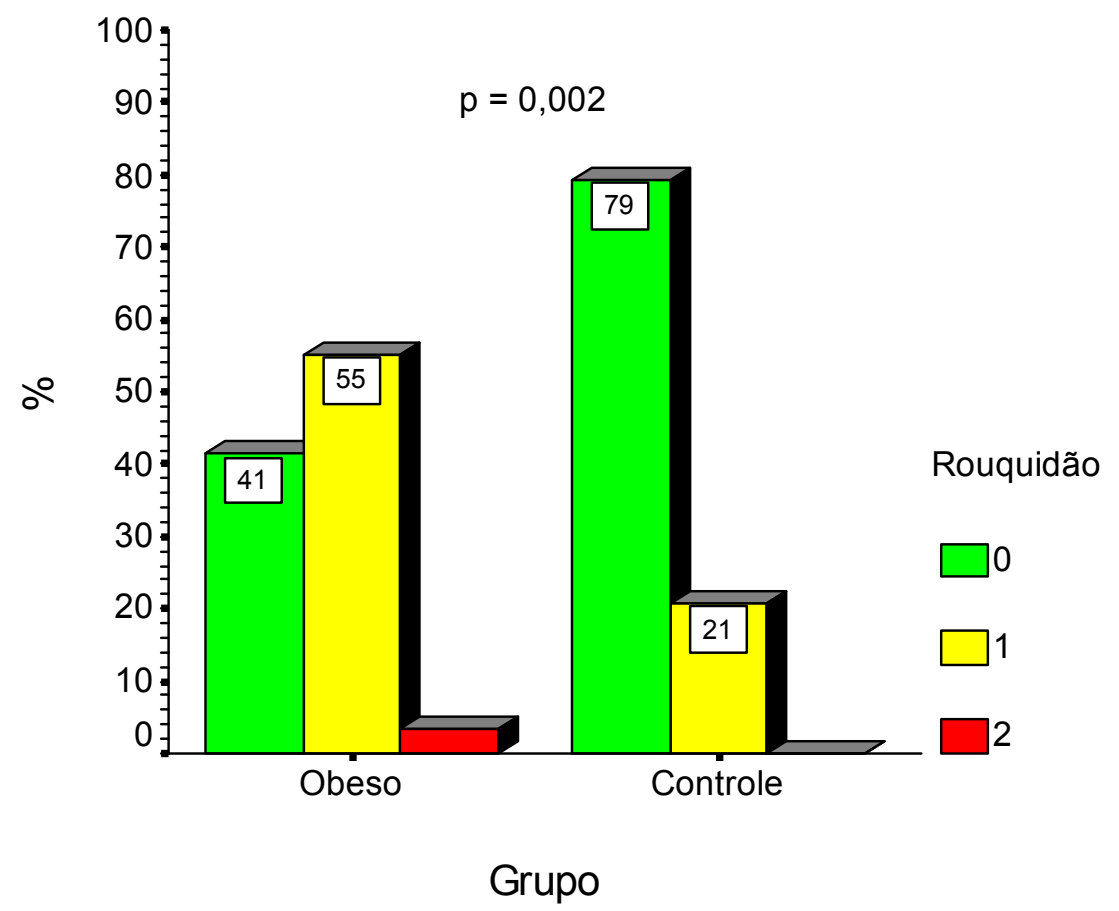

FIGURA 15 - Prevalências dos graus 0,1 e 2 de rouquidão entre os grupos obeso e controle, após exclusão de 16 pares obeso-controle que apresentavam lesões à laringoscopia.

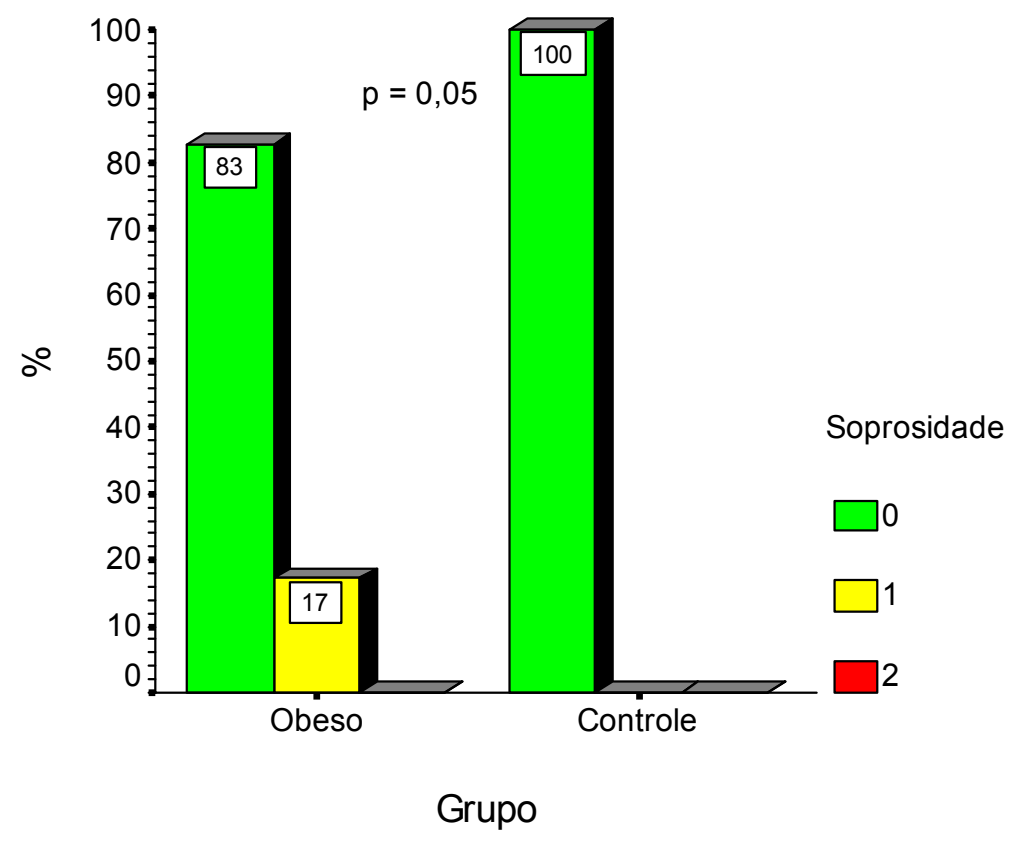

FIGURA 16 - Prevalências dos graus 0,1 e 2 de soprosidade entre os grupos obeso e controle, após exclusão de 16 pares obeso-controle que apresentavam lesões à laringoscopia. 


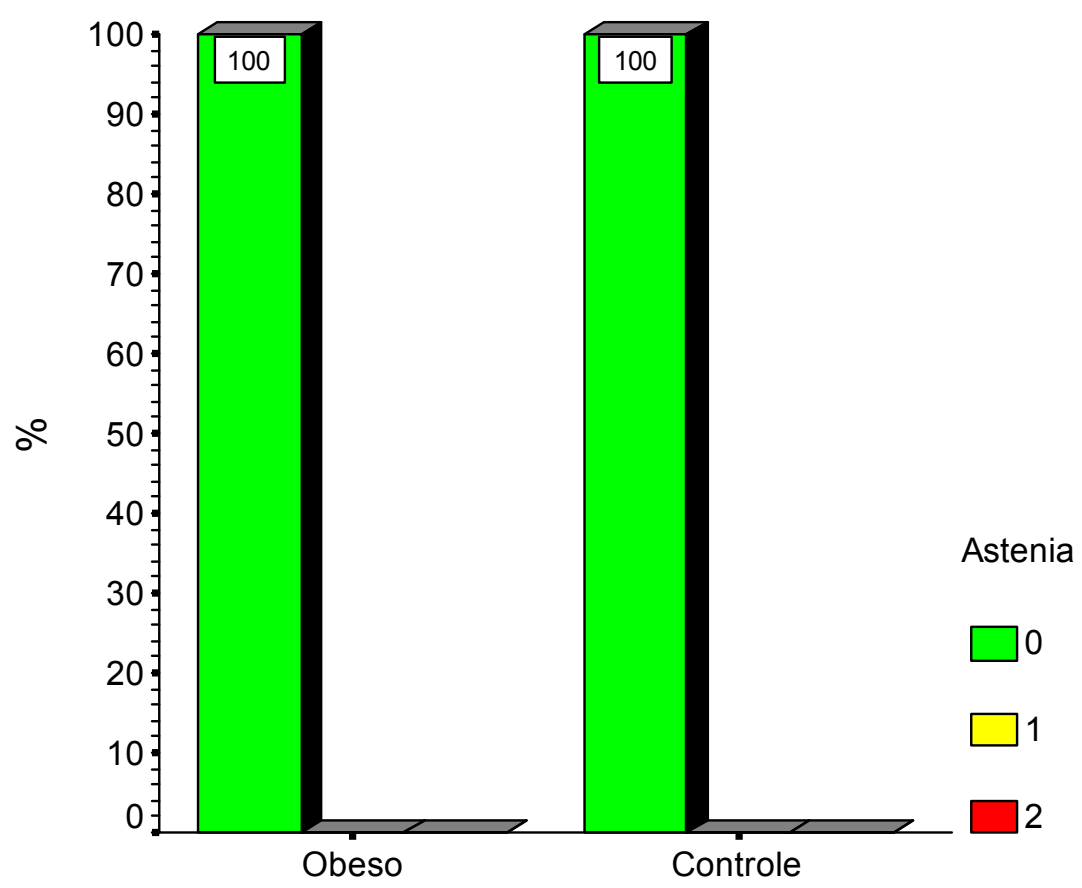

FIGURA 17 - Prevalências dos graus 0, 1 e 2 de astenia entre os grupos obeso e controle, após exclusão de 16 pares obeso-controle que apresentavam lesões à laringoscopia.

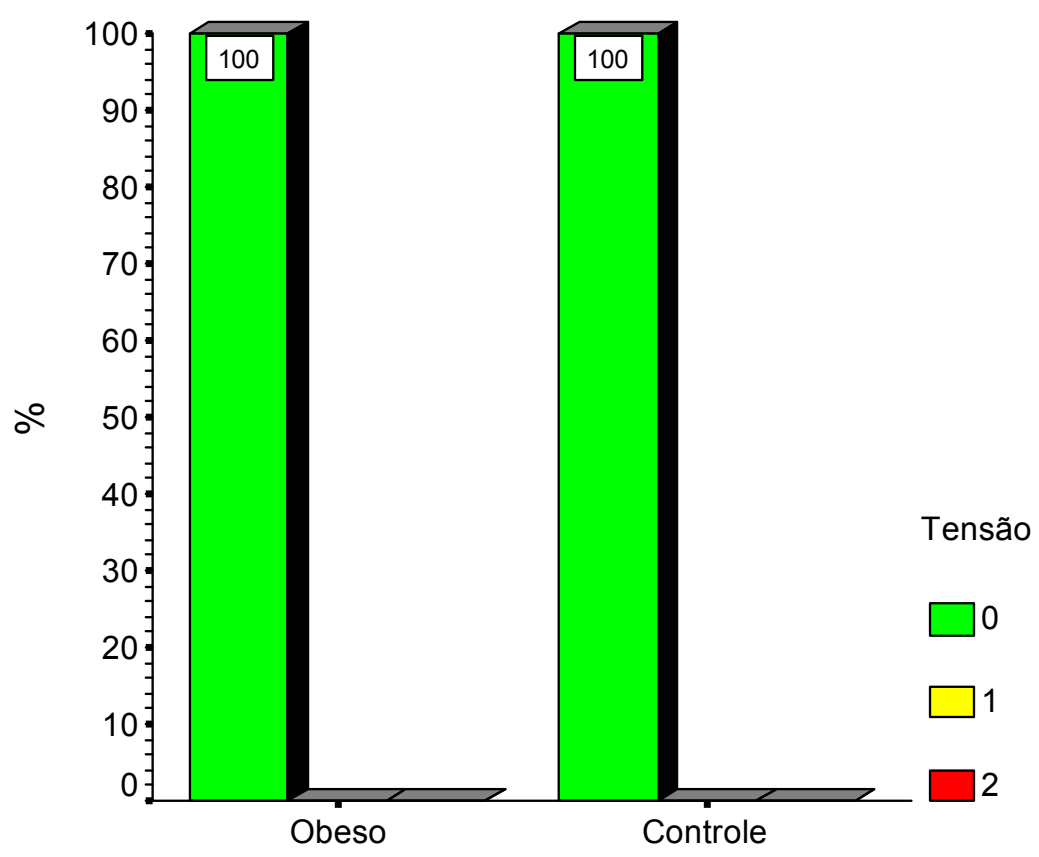

FIGURA 18 - Prevalências dos graus 0,1 e 2 de tensão entre os grupos obeso e controle, após exclusão de 16 pares obeso-controle que apresentavam lesões à laringoscopia. 
TABELA 7: Prevalência de "Vocal fry", Estrangulamento e Ressonância não equilibrada entre os grupos obeso e controle, após a exclusão de 16 pares obeso-controle com lesão de laringe à laringoscopia.

\begin{tabular}{|l|c|c|c|}
\hline & \multicolumn{2}{|c|}{ Grupo } & \\
\hline & $\begin{array}{c}\text { Obeso } \\
(\mathrm{n}=29)\end{array}$ & $\begin{array}{c}\text { Controle } \\
(\mathrm{n}=29)\end{array}$ & $p$ \\
\hline “Vocal fry" & $5(17,2 \%)$ & $3(10,3 \%)$ & 0,7 \\
\hline Estrangulamento & $5(17,2 \%)$ & $0(0,0 \%)$ & 0,07 \\
\hline Ressonância não-equilibrada & $21(72,4 \%)$ & $14(48,3 \%)$ & 0,06 \\
\hline
\end{tabular}

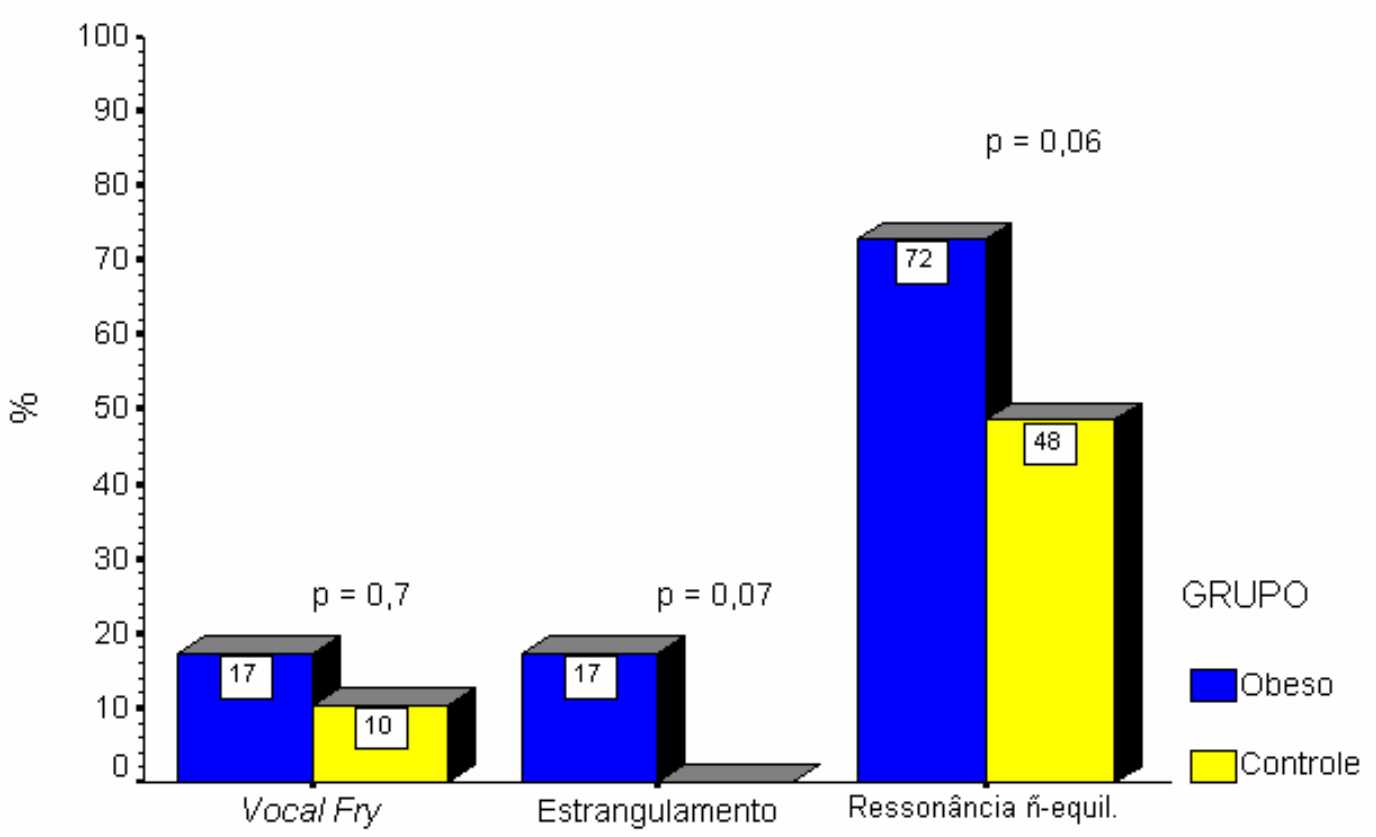

FIGURA 19 - Prevalência de "Vocal Fry", Estrangulamento e Ressonância não equilibrada entre os grupos obeso e controle, após a exclusão de 16 pares obesocontrole com lesões laríngeas à laringoscopia. 
TABELA 8: Análise acústica dos indivíduos estudados sem lesões laríngeas.

\begin{tabular}{|c|c|c|c|}
\hline & \multicolumn{2}{|c|}{ Grupo } & \multirow[b]{2}{*}{$p$} \\
\hline & $\begin{array}{l}\text { Obeso } \\
(n=29)\end{array}$ & $\begin{array}{l}\text { Controle } \\
(n=29)\end{array}$ & \\
\hline $\begin{array}{l}\text { Freqüência Fundamental } \\
\text { (Hz) } \\
\text { Homens }(n=9) \\
\text { Mulheres }(n=20)\end{array}$ & $\begin{array}{l}119,4(114,4-144,8) \\
190,7(172,6-207,6)\end{array}$ & $\begin{array}{l}123,7(114,0-130,6) \\
205,2(192,6-222,0)\end{array}$ & $\begin{array}{l}0,59 \\
0,025\end{array}$ \\
\hline $\begin{array}{l}\text { "Jitter" } \\
\text { Normal } \\
\text { Alterado }\end{array}$ & $\begin{array}{l}16(55,2 \%) \\
13(44,8 \%)\end{array}$ & $\begin{array}{c}29(100,0 \%) \\
0(0,0 \%)\end{array}$ & $<0,001$ \\
\hline $\begin{array}{c}\text { "Shimmer" } \\
\text { Normal } \\
\text { Alterado }\end{array}$ & $\begin{array}{l}15(51,7 \%) \\
14(48,3 \%)\end{array}$ & $\begin{array}{c}29(100,0 \%) \\
0(0,0 \%)\end{array}$ & $<0,001$ \\
\hline $\begin{array}{l}\text { Ruído } \\
\text { Normal } \\
\text { Alterado }\end{array}$ & $\begin{array}{l}11(37,9 \%) \\
18(62,1 \%)\end{array}$ & $\begin{array}{c}29(100,0 \%) \\
0(0,0 \%)\end{array}$ & $<0,001$ \\
\hline $\begin{array}{l}\text { Tempo máximo fonatório } \\
\text { (seg) } \\
\text { Homens }(n=9) \\
\text { Mulheres }(n=20)\end{array}$ & $\begin{array}{l}9,0(5,5-11,0) \\
7,0(5,0-8,8)\end{array}$ & $\begin{array}{c}15,0(10,5-17,5) \\
14(11,0-17,8)\end{array}$ & $\begin{aligned} & 0,1 \\
< & 0,001\end{aligned}$ \\
\hline
\end{tabular}




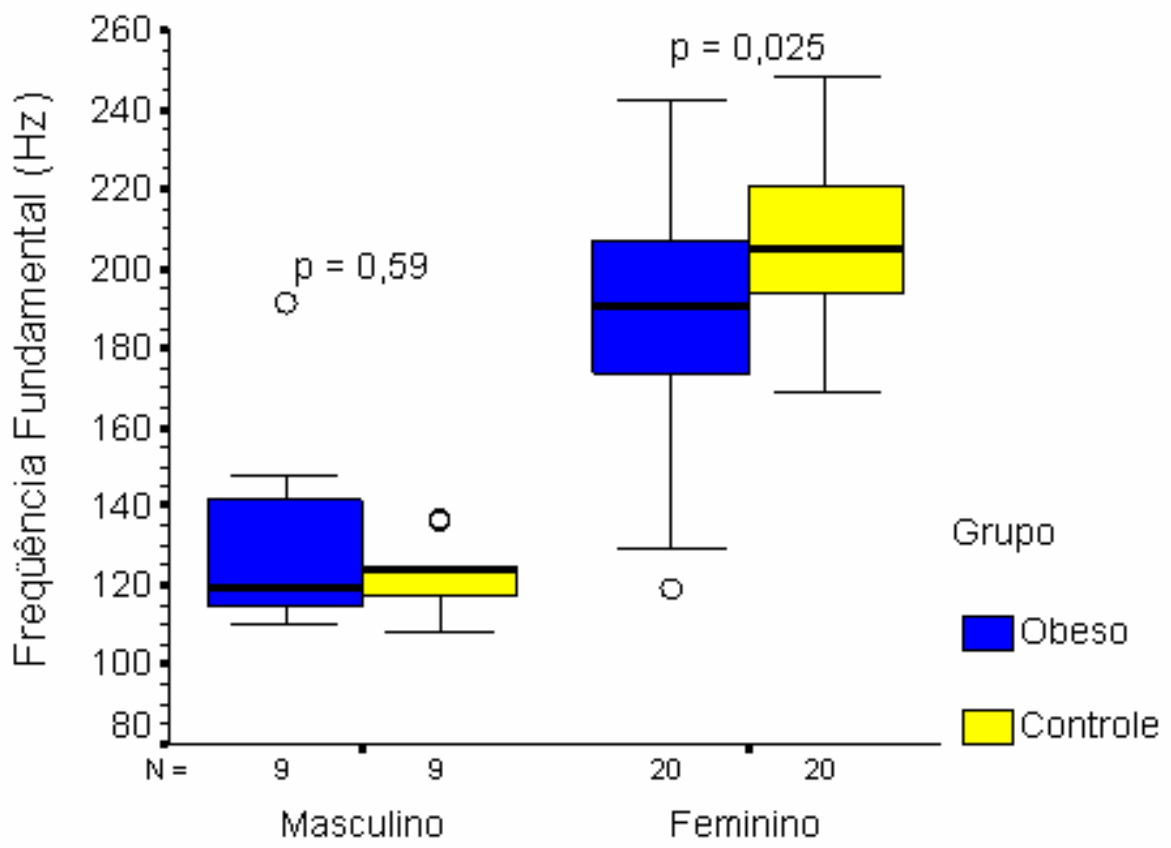

Sexo

FIGURA 20 - Boxplot da Freqüência Fundamental $(\mathrm{Hz})$ entre os grupos de obeso e controle agrupados de acordo com o sexo, após exclusão de 16 pares obesocontrole que apresentavam lesões à laringoscopia. Cada caixa representa a mediana, quartis e valores extremos dentro de uma categoria. "Outliers" estão representados como círculos ou asteriscos. Valores de $p$ obtidos do teste não paramétrico de Wilcoxon.

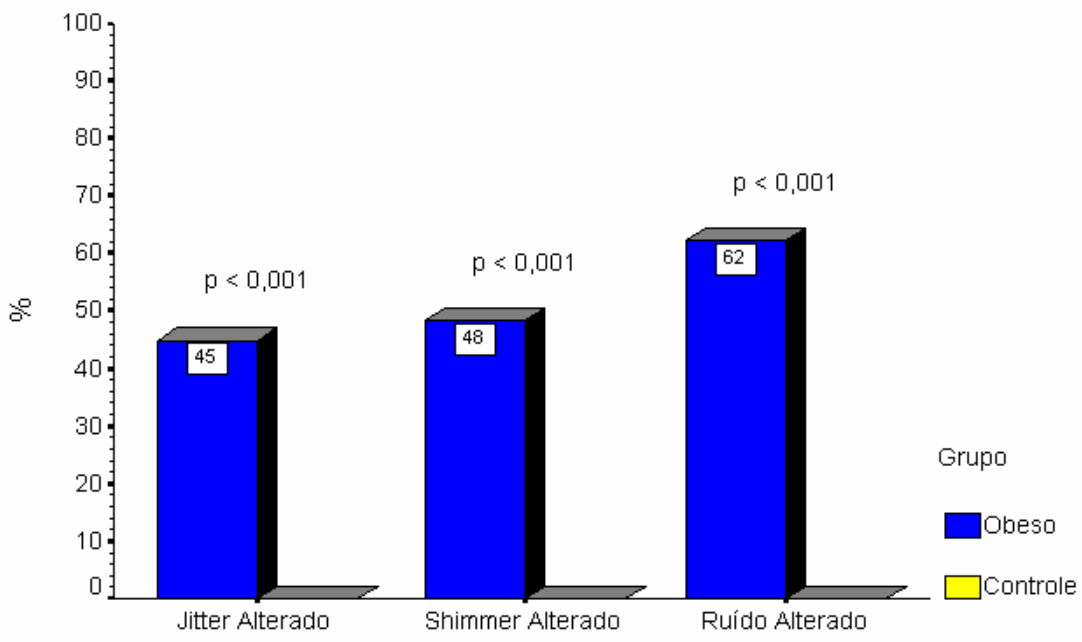

FIGURA 21 - Prevalência de "Jitter", "Shimmer" e Ruído alterados entre os grupos obeso e controle, após exclusão de 16 pares obeso-controle que apresentavam lesões à laringoscopia. 


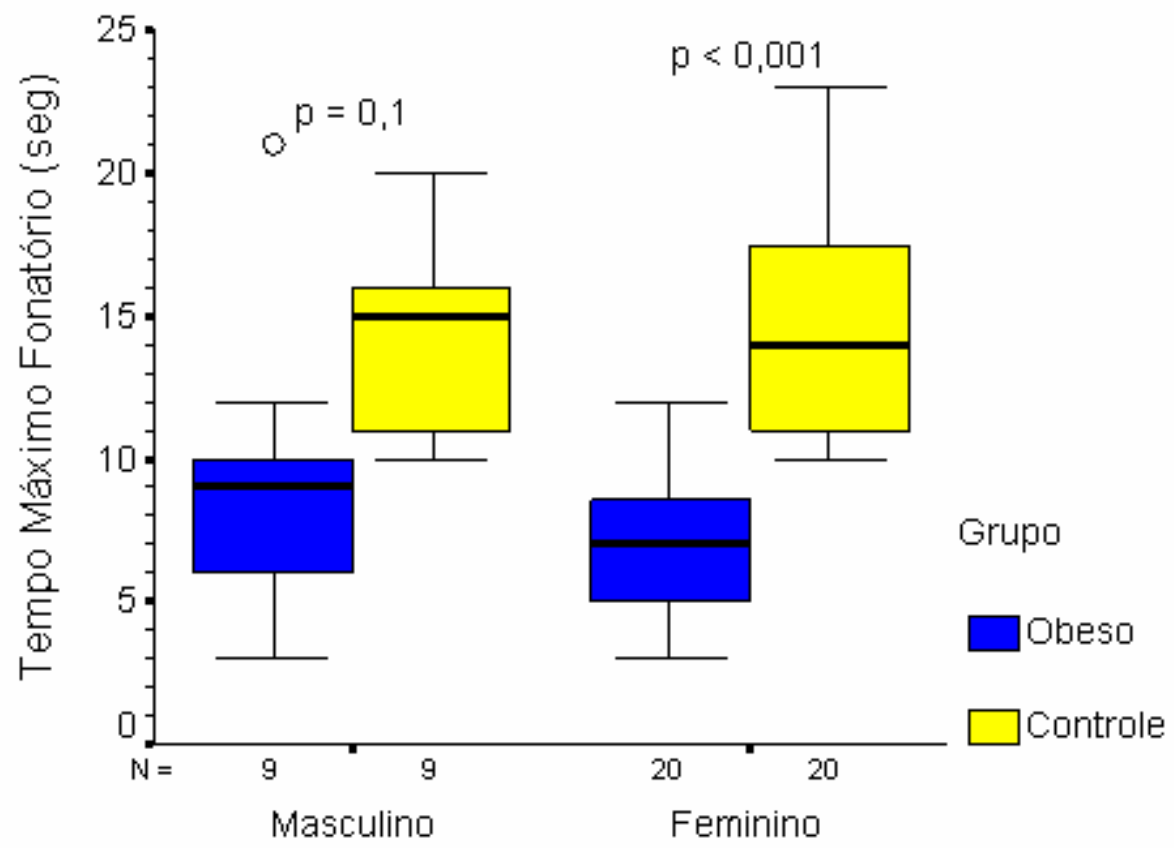

Sexo

FIGURA 22 - Boxplot do Tempo Máximo Fonatório (segundos) entre os grupos de obeso e controle agrupados de acordo com o sexo, após exclusão de 16 pares obeso-controle que apresentavam lesões à laringoscopia. Cada caixa representa a mediana, quartis e valores extremos dentro de uma categoria. "Outliers" estão representados como círculos ou asteriscos. Valores de $p$ obtidos do teste não paramétrico de Wilcoxon.

TABELA 9: Análise da força de associação (risco relativo) das alterações perceptivo-auditivas e acústicas da voz e obesidade em relação ao grupo controle.

\begin{tabular}{|l|c|}
\hline Alteração & RR (IC 95\%) \\
\hline $\mathrm{G} \geq 1$ & $2,3(1,4-4,0)$ \\
\hline $\mathrm{I} \geq 1$ & $2,1(1,3-3,6)$ \\
\hline $\mathrm{R} \geq 1$ & $2,2(1,3-3,6)$ \\
\hline $\mathrm{B} \geq 1$ & $2,2(1,6-3,0)$ \\
\hline $\mathrm{A} \geq 1$ & - \\
\hline $\mathrm{S} \geq 1$ & - \\
\hline "Vocal fry" & $1,3(0,7-2,4)$ \\
\hline Estrangulamento & $1,9(1,4-2,5)$ \\
\hline Ressonância Não equilibrada & $1,7(0,9-3,2)$ \\
\hline "Jitter" Alterado & $2,8(1,9-4,2)$ \\
\hline "Shimmer" Alterado & $2,9(1,9-4,4)$ \\
\hline Ruído Alterado & $2,0(1,6-2,7)$ \\
\hline
\end{tabular}




\section{DISCUSSÃO}

Este estudo procurou avaliar 45 indivíduos adultos voluntários portadores de obesidade mórbida pareados com adultos voluntários não obesos no sentido de caracterizar a voz daqueles que apresentavam obesidade mórbida.

Quanto ao grupo como um todo observou-se lesões laríngeas benignas nos portadores de obesidade mórbida com maior freqüência do que no grupo controle (TABELA 2). A presença de lesões laríngeas no Grupo de Obesos (GO) foi duas vezes mais prevalente $(26,7 \%$ versus 13,3\%) que no Grupo Controle (GC), embora esta diferença não tenha sido estatisticamente significante $(p=0,11)$. Isso pode ser explicado pela diminuição do fluxo aéreo apresentado pelo GO expressado pelos reduzidos tempos máximos fonatórios encontrados neste estudo, o que os levaria a fazer um esforço fonatório maior, propiciando assim o aparecimento de lesões laríngeas. Além disso, as lesões podem ter sido mais freqüentes devido a um viés de seleção, ou seja, já que o estudo foi composto por voluntários, é possível que aqueles com queixa vocal tivessem maior interesse em participar do estudo.

Tanto no GO quanto no GC foram evidenciados sinais laríngeos sugestivos de lesão por RGE, conforme a TABELA 2. Os achados de 
sinais laríngeos sugestivos de lesão por RGE foram caracterizados segundo critério de KOUFMAN (1995), quando ocorria paquidermia, hiperemia e/ou edema interaritenoideo; e/ou pseudo-sulco nas pregas vocais. GOMES ESCUDERO et al., 2002, referem que o esfíncter esofágico inferior hipotônico, mobilidade esofágica inefetiva e presença de hérnia hiatal são mecanismos da fisiopatologia propostos como indutores do RGE em pacientes obesos. Esse pode ser outro motivo pelo qual o GO apresentou maior freqüência de sinais laríngeos sugestivos de lesão por RGE em relação ao GC. Como não foi realizado nenhum estudo em relação ao próprio RGE (PH Metria, endoscopia), pois esse não era o intuito da pesquisa, não se pode fazer maiores afirmações quanto ao RGE.

Quanto aos exames da voz propriamente ditos deve-se realçar que sua análise foi realizada por três fonoaudiólogas e decidido por consenso sem que se soubesse a origem do grupo ao qual os pacientes pertenciam.

Em relação à avaliação perceptivo-auditiva realizada através da escala GIRBAS, é evidente a diferença observada entre o GO e o GC, onde alguns parâmetros estudados estavam alterados. Observa-se claramente que a qualidade vocal do GO é significativamente alterada em relação aos indivíduos do GC. Pode-se observar como demonstrado na TABELA 3, que 66\% dos indivíduos do GO apresentaram algum grau de disfonia (G) em suas vozes, enquanto que no GC apenas $27 \%$ dos indivíduos apresentaram algum grau de disfonia $(p<0,001)$. Esse fato pode se dar decorrente do 
aumento de massa das pregas vocais encontrados nos indivíduos obesos (SATALOFF, 1987).

Quanto à qualidade vocal instável e soprosa, verificou-se também que em $44 \%$ do GO e $9 \%$ do GC apresentavam instabilidade em suas vozes, e que em $27 \%$ dos indivíduos do GO e em $2 \%$ dos indivíduos do GC havia presença de soprosidade à fonação. Esses fatos podem ser explicados em decorrência da reduzida pressão subglótica observada nos reduzidos tempos máximos fonatórios (BORTOLOTTI \& ANDRADA E SILVA, 2005).

Quanto a rouquidão (R) observou-se que $62 \%$ do $\mathrm{GO}$ e $27 \%$ do $\mathrm{GC}$ apresentam essa alteração. A voz rouca pode ser explicada por dois fatores: irregularidade de vibração das pregas vocais devido ao reduzido tempo máximo fonatório (TABELA 3) e/ou aumento de massa laríngea do trato vocal, fatores estes que podemos observar nos indivíduos portadores de obesidade mórbida, como citado por BEHLAU e PONTES, 1995. A rouquidão pode, também, ser explicada por meio dos ruídos que são produzidos independentemente dos movimentos ondulatórios da mucosa das pregas vocais, como, por exemplo, o ruído realizado pelos tecidos moles da orofaringe, aumentados nos indivíduos obesos, como observado em estudos ALOÉ et al., 1997; MOURA, 1996.

Em relação à astenia $(A)$ e tensão $(S)$ nenhum dos indivíduos deste estudo apresentou nenhum grau destes parâmetros em suas vozes (100\%). 
Assim, os indivíduos portadores de obesidade mórbida têm com maior freqüência em suas vozes: rouquidão (62\%), soprosidade (27\%) e instabilidade fonatória (44\%) (TABELA 3), do que os indivíduos do GC.

Esses achados concordam com os achados referentes à qualidade vocal do estudo de BORTOLOTTI \& ANDRADA E SILVA, 2005, estudando 21 mulheres obesas que apresentaram qualidade vocal predominantemente rouca $(76 \%)$, soprosa $(52 \%)$ e crepitante $(43 \%)$.

Quanto ao "Vocal fry", foi observado em 18\% dos indivíduos do GO e $11 \%$ no GC. Esse parâmetro é esperado para essa população, uma vez que os TMF reduzidos e a redução da pressão subglótica causariam uma voz crepitante ou "vocal fry" (TABELA 4). Embora esse dado não tenha sido estatisticamente significante esse achado foi mais prevalente no GO do que no GC (HIRANO \& BLESS, 1993).

Em relação ao Estrangulamento, 22\% indivíduos portadores de obesidade mórbida apresentaram-no aos finais das emissões $(p<0,001)$, como observado na TABELA 4. O estrangulamento da voz ao final da emissão significa que a voz está tensa e que a vibração da mucosa das pregas vocais é reduzida. Isto pode estar associado ao tempo máximo de fonação diminuído em que o fluxo de ar vai diminuindo e o indivíduo faz certa força e estrangula, assim, o final da emissão. HIRANO, KOIKE e VON LEDEN (1968) avaliaram 25 indivíduos de cada gênero e definiram que 
valores de tempo máximo de fonação inferiores a10s são considerados patológicos esses dados vão de encontro ao atual estudo.

A Ressonância não equilibrada encontrada no GO, esteve presente em $32 \%$ destes indivíduos. Esse fato pode ser explicado pelo aumento de massa no trato vocal, o que favorece uma ressonância baixa (TABELA 4). Segundo BEHLAU, 2001, a voz parece estar presa na garganta e não apresenta riqueza de harmônicos e projeção adequada no ambiente.

Quanto à análise acústica da voz, conforme apresentado na TABELA 5, diversos parâmetros encontraram-se alterados.

Em relação à Freqüência Fundamental (Fo) observa-se, no sexo masculino, diferença significante do GO em relação ao GC. Porém, quando avaliamos apenas o sexo feminino esta diferença não foi significante. Embora não tenha sido significante observamos que a Fo do GO foi mais baixa do que no GC, provavelmente isso se deve ao aumento de massa das pregas vocais pela própria obesidade, onde se espera que a Fo dos indivíduos portadores de obesidade mórbida seja mais baixa, caracterizando assim uma voz mais agravada. E isso não foi observado no sexo masculino, onde também era esperado um agravamento da voz. Isso pode ser explicado pelas lesões apresentadas pelo GO, onde algumas vezes a Fo pode estar mais elevada devido à tensão nas pregas vocais. Esse dado encontrado no sexo feminino corrobora com os achados de BEHLAU, TOSI, 
PONTES (1985), que em estudo referem que a freqüência fundamental média, para falantes do português brasileiro, para adultos do sexo masculino é de $113 \mathrm{~Hz}$ e para adultos do sexo feminino é de $204 \mathrm{~Hz}$.

O “Jitter", o "Shimmer" e o Ruído foram significativamente diferentes no GO em relação ao GC.

Observa-se que 44\%, $38 \%$ e $64 \%$ dos indivíduos do GO apresentaram respectivamente "jitter", "shimmer" e ruído alterados. Estes dados mostram que os indivíduos analisados (GO) apresentam vozes mais aperiódicas em relação ao grupo controle. Isto nos leva a pensar que os indivíduos do GO podem ter aumento de massa do trato laríngeo e vocal, o que modificaria os movimentos vibratórios da mucosa das pregas vocais ocasionando assim tal aperiodicidade. BEHLAU refere que, quando há lesões que afetam as pregas vocais, suas vibrações mostram aumento na aperiodicidade, o que é refletido em valores aumentados de "jitter" e "shimmer".

BEHLAU, 2001, refere que as vozes normais apresentam certa quantidade de ruído esperada, relacionada às perturbações da produção da voz, mas não quantidades elevadas de ruído como foi encontrado nos indivíduos portadores de obesidade mórbida. 
Quanto ao Tempo Máximo Fonatório (TMF) que é representativo da eficiência glótica em relação à respiração, pode-se observar como referido na TABELA 5, que o GO teve TMF inferiores em relação ao GC, tanto no sexo masculino quanto no feminino, traduzindo, neste caso, a influência da pletora torácica do indivíduo obeso no fenômeno respiratório. Este fato é reforçado pela alteração detectada no estrangulamento que expressa a mesma dificuldade do indivíduo obeso em realizar movimentos respiratórios na mesma amplitude dos indivíduos normais. YANAGIHARA \& VON LEDEN, 1967, afirmam que o tempo máximo de fonação é alcançado por três fatores fisiológicos: capacidade do ar total disponível para a produção da voz, força expiratória e ajuste da laringe para o uso eficiente do ar, isto é, resistência glótica.

Tanto nos homens quanto nas mulheres do GO esse dado é significativamente menor (8 e 7 seg. respectivamente), essa diferença existe, e clinicamente é grande, como está apresentado na FIGURA X. BEHLAU \& PONTES, 1995, referem que valores menores que 10 segundos devem ser considerados não-normais com alta significância.

Assim, podemos pensar que o valor reduzido dos TMF dos indivíduos portadores de obesidade mórbida possa estar relacionado ao elevado peso destes indivíduos, levando a um acúmulo de gordura na laringe, o que causa uma dificuldade nos ajustes das forças mioelásticas e aerodinâmicas da laringe, para uma boa produção vocal. MOURA, 1996, refere que os 
indivíduos obesos apresentam deposição anormal de gordura na úvula, palato mole, paredes laterais e posterior da faringe, e região posterior de língua, estruturas estas pertencentes à composição do trato vocal (MOURA, 1996).

Diante destes dados podemos dizer que a qualidade vocal dos indivíduos portadores de obesidade mórbida é estatisticamente significante mais alterada que no grupo controle.

Para confirmar que os achados encontrados no GO eram decorrentes da própria obesidade e não de outros fatores, optou-se realizar também a análise dos parâmetros vocais excluindo-se os 16 pares obeso-controle que apresentavam lesões laríngeas, para que a presença das mesmas não interferisse nos resultados.

Estes dados relacionados nas tabelas 6,7 e 8 e figuras $X$ embora numericamente diferentes, não tiveram significado estatístico, ou seja, os valores relativos a instabilidade, rouquidão, soprosidade, presença de "vocal fry", estrangulamento, ressonância não equilibrada, Fo, "jitter", "shimmer", ruído e TMF foram diferentes entre os $\mathrm{GO}$ em relação ao GC mesmo excluindo fatores como lesões laríngeas.

Isto sem duvida reforça o conceito e a possibilidade de que as alterações da voz dos pacientes portadores de obesidade mórbida sejam 
decorrentes da sua própria condição física e não de outras alterações porventura existentes.

Com estes resultados pode-se inferir que o paciente portador de obesidade mórbida tem alterações da voz decorrentes de sua própria situação ponderal, embora existam outros fatores fisiológicos ou patológicos decorrentes desta mesma situação que podem interferir, como é o caso do RGE. Para tanto porém outros estudos enfocando estes fatores em particular deveriam ser realizados. Sem dúvida, como maior perspectiva desta investigação, deveria ser o prosseguimento de estudos que analisassem eventuais mudanças vocais nestes pacientes agora operados com diminuição do peso em níveis próximos da normalidade. 


\section{CONCLUSÕES}

A partir da análise dos resultados apresentados neste estudo, podese concluir que a voz do indivíduo portador de obesidade é caracterizada por:

1. Qualidade vocal rouca, soprosa e com instabilidade fonatória.

2. Presença de estrangulamento da voz ao final das emissões.

3. "Jitter", "Shimmer" e Ruído alterados.

4. Tempos Máximos Fonatórios diminuídos.

5. A voz do indivíduo portador de obesidade mórbida apresenta características próprias, com alterações significantes em relação aos indivíduos não obesos. 


\section{REFERÊNCIAS BIBLIOGRÁFICAS}

Aloé F, Pedroso A, Tavares S, Barbosa RC. Ronco e síndrome da apnéia obstrutiva do sono. Fono Atual. 1997;1(1):34-9.

Akerman MJ, et al. Relationship of asthma severity and obesity. J Asthma. 2004;41(5):521-6.

Antipatis VJ, Gill TP. Obesity as global problem. In: Bjorntorp P. International text book of obesity. Chichester (US): John Wiley \& Sons; 2001. p3-22.

Aronson AE. Clinical voice disorders: na interdisciplinary approach. 2nd ed. New York: Thieme Verlag; 1985.

Baken RJ. Clinical measurements of speech and voice. Boston: College-Hill; 1987. p.542-7.

Behlau M. Uma análise das vogais do português brasileiro falado em São Paulo: perceptual, espectrográfica de formantes e computadorizada da freqüência fundamental [dissertação]. São Paulo: Escola Paulista de Medicina; 1984.

Behlau M, Tosi $O$, Pontes $P$. Determinação da freqüência fundamental e suas variações em altura ("jitter") e intensidade ("shimmer"), para falantes do português brasileiro. Acta AWHO. 1985;4:5. 
Behlau M, Pontes P. Avaliação e tratamento das disfonias. São Paulo: Lovise; 1995.

Behlau M, Madazio G, Feijó D, Pontes P. Avaliação de voz. In: Voz: o livro do especialista. São Paulo: Revinter; 2001. v.1.

Bittencourt LRA. Tratamento clínico da síndrome da apnéia e hipopnéia obstrutiva do sono. In: Campos $\mathrm{CAH}$, Costa HOO, Tratado de otorrinolaringologia. São Paulo: Rocca; 2002. v.3, cap. 58.

Bortolotti P, Andrada e Silva MA. Caracterização da voz de um grupo de mulheres com obesidade mórbida acompanhadas no setor de cirurgia bariátrica da Irmandade Santa Casa de Misericórdia de São Paulo. Distúrbios da Comunicação, São Paulo. 2005 ago.;17(2):149-60.

Colton R, Casper J. Compreendendo os problemas de voz - uma perspectiva fisiológica ao diagnóstico a ao tratamento. Porto Alegre: Artes Médicas; 1996.

Cooper M. Modernas técnicas de rehabilitación vocal. Buenos Aires: Panamericana; 1974.

Dallacqua RM. Obesos perdem peso e mudam a voz [internet]. Agenda de Notícias da Uniara, Centro Universitário de Araraquara, 2004. Disponível em: ?????? 
Dejonckere P, Remacle M, Freznel E. Reliability and relevance of differentiated perceptual evaluation of pathological voice quality. In: Clemente MP, editor. Voice update. Amsterdam: Elsevier; 1996. p.321-4.

Di Francesco V, et al. Obesity and gastro-esophageal acid reflux: physiopathological mechanisms and role of gastric bariatric surgery. Obes Surg. 2004;14(8):1095-102.

Estill J. Basic figures and exercise manual. New York: Imagetech; 1992.

Fujita R, et al. Ronco e apnéia do sono. In: Campos CAH, Costa HOO. Tratado de otorrinolaringologia. São Paulo: Rocca; 2002. v.3, cap. 65.

Gomes Escudero O, et al. Obesity and gastroesophageal reflux disease. Rev Invest Clin. 2002;54(4):320-7.

Hirano $\mathrm{M}$, Koike $\mathrm{Y}$, Von Leden $\mathrm{H}$. Maximum phonation time and air usage during phonation. Folia Phoniatr. 1968;20:185-201.

Hirano M. Psycho-acoustic evaluation of voice. In: Clinical examination of voice. New York: Springer Verlag; 1981.

Hirano M, Bless DM. Videoestroboscopy examination of the larynx. San Diego: Singular; 1993.

Isshiki N, Yanagihara N, Morimoto M. Approach to the objective diagnosis of hoarseness. Folia Phoniatr. 1966;18:383-400. 
Koufmann J. Gastroesophageal reflux and voice disorders. In: Rubin JS, Sataloff RT, Korovin G, Gould WJ. Diagnosis and treatment of voice disorders. New York: Igaku-Shoin; 1995. p.161-75.

Mancini MC. Obstáculos diagnósticos e desafios terapêuticos no paciente obeso. Arq Bras Endocrinol Metab. 2001;45(6):1-44.

Moore DM, Juillard GJ, Ward PH. Early vocal cord carcinoma in obese patients: a surgical lesion. Laryngoscope, 1987; 97(6):686-8.

Moura SMGPT. Efeito agudo do CPAP nasal no controle ventilatório e nacapacidade de exercício de pacientes normocápnicos com síndrome da apnéia do sono obstrutiva [dissertação]. São Paulo: Universidade Estadual Paulista de Medicina; 1996.

Pellegrini M, Marzocca G. Reflux-like dyspepsia in obese patients. Recenti Prog Med. 2002;93(12):681.

Pinho SMR. Avaliação e tratamento da voz. In: Fundamentos em fonoaudiologia - tratando os distúrbios da voz. Rio de Janeiro: Guanabara Koogan; 1998.

Pinho SMR, Camargo Z. Introdução à análise acústica da voz e da fala. In: Tópicos em voz. Rio de Janeiro: Guanabara Koogan; 2001.

Ross J, Noordji P, Woo P. Voice disorders in patients with suspected laryngo-pharyngeal reflux disease. J Voice. 1998;????? 
Sataloff RT. The professional voice: anatomy, function and general health. $J$ Voice. 1987;1(1):92-104.

Sataloff R, Castell O, Satalof M, Spiegell J, Hawkshaw M. Reflux and other gastroenterologic conditions that may affect the voice. In: Professional voice: the science and art to clinical care. 2nd ed. San Diego: Singular; 1997.

Simard B, et al. Asthma and sleep apnea in patients with morbid obesity: outcome after bariatric surgery. Obes Surg. 2004;14(10):1381-8.

Tarneaud J. Traité pratique de phonologie et phoniatrie. Paris: Maloine; 1941.

Toohill J, Kuhn J. Role of refluxed acid in pathogenesis of laryngeal disorders. Am J Med. 1997;??????.

Yanagihara N, Von Leden M. Respiration and phonation. Folia Phoniatr. 1967;19:153-66.

Zemlin W. Speech and hearing science. New Jersey (US): Prentice Hall; 1988. 


\section{ANEXOS}

\section{ANEXO 1}

Setor de Fonoaudiologia da Disciplina de Otorrinolaringologia

Hospital das Clínicas-FMUSP

\section{Questionário da Pesquisa- Alteração Vocal nos Indivíduos}

Portadores de Obesidade Mórbida

\section{PRÉ-CIRURGIA}

Nome do paciente:

Idade:

Peso Atual:

Altura: IMC:

Sexo: $\overline{F(~) ~ M(~) ~}$

Escolaridade:

Profissão:

Endereço:

CEP:

Tel:

1) Você tem alguma queixa relacionada à voz? (S) (N)

2) Apresenta rouquidão? (S) (N)

3) Há quanto tempo?

4) Você sabe qual foi a causa?

5) Foi progressivo ou de repente?

6) Quais os sintomas que apresenta?

7) Quando a voz é pior?

8) De 0 a 10, que nota você dá para sua voz?

9) Já fez fonoterapia? (S) (N)

10)Já procurou um Médico Otorrino? (S) (N) 
11)Tem queixas relacionadas ao Refluxo Gastro Esofágico? (S) sensação de corpo estranho na garganta( );

salivação excessiva/espessa( ); mau hálito( ); boca seca/amarga( ); aftas( ); azia( ); queimação( )

12)Já procurou um Gastro devido ao Refluxo Gastro Esofágico?

(S) $\quad(\mathrm{N})$

13)O que você acha da sua voz?

14)Faz uso intenso da voz? (S) (N)

15)Piora após esse uso? (S) (N)

16)Você percebe alguma mudança de voz após a alimentação?(S)

17) Você tem falta de ar? (S) (N)

18)Você tem dificuldades para engolir? (S) (N)

19)Engasga com freqüência? (S) (N)

20) O seu problema de voz te impossibilita de fazer alguma atividade?

(S) (N)

21)Já realizou alguma cirurgia de laringe, cardíaca, torácica ou tireóide? (S) (N)

22)Respira com a boca aberta? (S) (N)

23) Ronca? (S) (N)

24) Tem Asma? (S) (N)

25) Fuma? (S) (N)

26) Tem apnéia (acorda sufocado, pára de respirar à noite)? (S) (N) 


\author{
ANEXO 2 \\ HOSPITAL DAS CLÍNICAS \\ DA \\ FACULDADE DE MEDICINA DA UNIVERSIDADE DE SÃO PAULO
}

TERMO DE CONSENTIMENTO PÓS -INFORMAÇÃO

(Instruções para preenchimento no verso)

I - DADOS DE IDENTIFICAÇÃO DO SUJEITO DA PESQUISA OU RESPONSÁVEL LEGAL

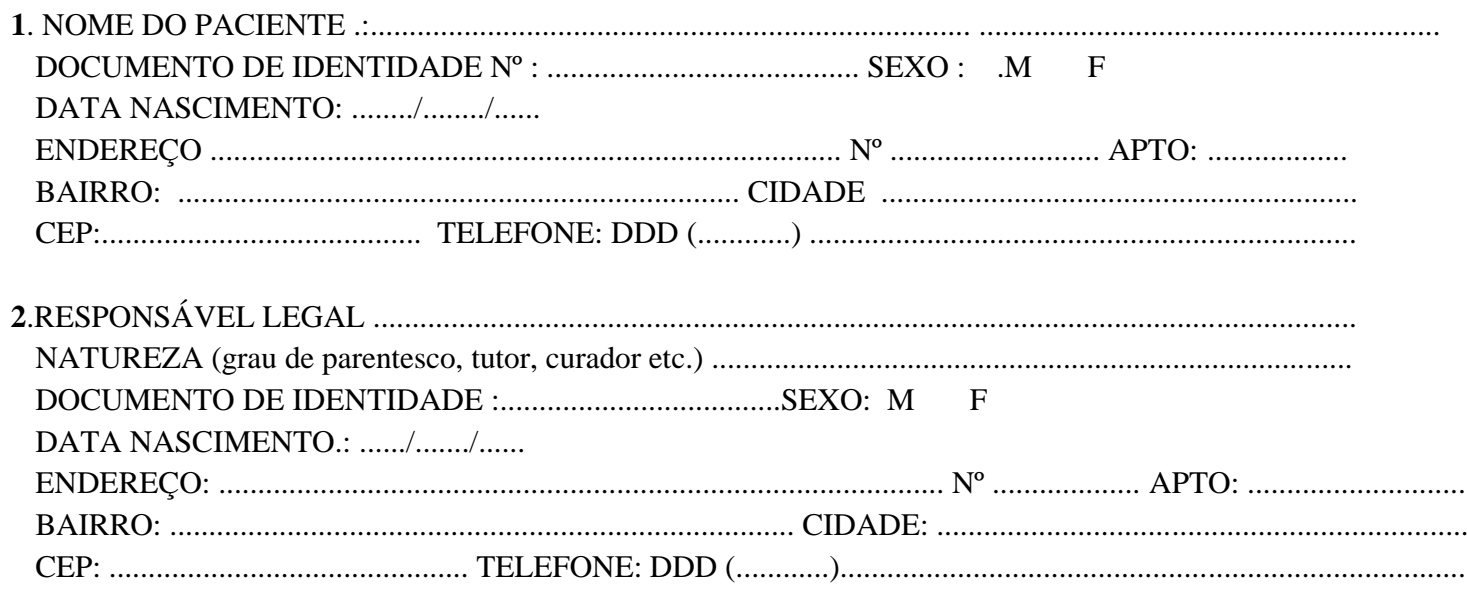

\title{
II - DADOS SOBRE A PESQUISA CIENTÍFICA
}

1. TÍTULO DO PROTOCOLO DE PESQUISA :

“Avaliação Vocal em pacientes portadores de obesidade mórbida”

2. PESQUISADOR:

\section{Maria Gabriela Bernardo da Cunha}

\section{CARGO/FUNÇÃO: Fonoaudióloga INSCRIÇÃO CONSELHO REGIONAL No 9543/SP}

UNIDADE DO HCFMUSP: Setor de Fonoaudiologia do Ambulatório de

\section{Otorrinolaringologia}

3. AVALIAÇÃO DO RISCO DA PESQUISA:

\begin{tabular}{|c|c|c|c|c|}
\hline SEM RISCO & $\square$ & RISCO MÍNIMO & $\nabla$ & RISCO \\
\hline RISCO BAIXO & $\square$ & RISCO MAIOR & $\square$ & \\
\hline
\end{tabular}

(probabilidade de que o indivíduo sofra algum dano como conseqüência imediata ou tardia do estudo)

4.DURAÇÃO DA PESQUISA : 7 meses 
III - REGISTRO DAS EXPLICAÇÕES DO PESQUISADOR AO PACIENTE OU SEU REPRESENTANTE LEGAL SOBRE A PESQUISA, CONSIGNANDO:

1. justificativa e os objetivos da pesquisa ; 2 . procedimentos que serão utilizados e propósitos, incluindo a identificação dos procedimentos que são experimentais; 3 . desconfortos e riscos esperados; 4 . benefícios que poderão ser obtidos; $\mathbf{5}$. procedimentos alternativos que possam ser vantajosos para o indivíduo.

Caro paciente,

Esta-se e iniciando um estudo com o objetivo de avaliar a voz do portador de obesidade mórbida para verificar se há correlação entre obesidade e alteração na voz.

Será realizado um exame de laringoscopia para visualização das suas pregas vocais. Para este exame eventualmente poderá ser utilizado um spray anestésico em sua boca. Isto no máximo poderá causar a sensação de boca amarga e um pouco de adormecimento, sem maiores conseqüências. Este exame consiste na introdução de um aparelho bem fino, para visão das pregas vocais, por sobre a língua o que pode em alguns casos acarretar vontade de vomitar. Não se aconselha fazer o exame em indivíduos que sabidamente apresentam alergia a xilocaína, o que deverá ser informado. Também não poderão fazer ao exame aqueles que já tiveram no passado história prévia de edema de glote. Será também realizada uma gravação de sua voz em um computador para posterior análise, que não acarreta nenhum incômodo.

A sua identidade bem como o exame e a gravação da voz serão mantidos em sigilo.

O seu acompanhamento médico é independente da sua participação neste estudo, e seu atendimento não será prejudicado caso você não queira participar dele.

Sua participação é voluntária e você não receberá nenhuma remuneração ou benefícios.

Também poderá cancelar esta autorização a qualquer momento sem necessidade de justificar.

Este estudo não traz qualquer interferência ou prejuízo a sua saúde. 
IV - ESCLARECIMENTOS DADOS PELO PESQUISADOR SOBRE GARANTIAS DO SUJEITO DA PESQUISA:

1. acesso, a qualquer tempo, às informações sobre procedimentos, riscos e benefícios relacionados à pesquisa, inclusive para dirimir eventuais dúvidas.

2. liberdade de retirar seu consentimento a qualquer momento e de deixar de participar do estudo, sem que isto traga prejuízo à continuidade da assistência.

3. salvaguarda da confidencialidade, sigilo e privacidade.

4. disponibilidade de assistência no HCFMUSP, por eventuais danos à saúde, decorrentes da pesquisa.

5. viabilidade de indenização por eventuais danos à saúde decorrentes da pesquisa.

\section{INFORMAÇÕES DE NOMES, ENDEREÇOS E TELEFONES DOS RESPONSÁVEIS PELO ACOMPANHAMENTO DA PESQUISA, PARA CONTATO EM CASO DE INTERCORRÊNCIAS CLÍNICAS E REAÇÕES ADVERSAS.}

VI. OBSERVAÇÕES COMPLEMENTARES:

\section{VII - CONSENTIMENTO PÓS-ESCLARECIDO}

Declaro que, após convenientemente esclarecido pelo pesquisador e ter entendido o que me foi explicado, consinto em participar do presente Protocolo de Pesquisa

São Paulo, de de 20 


\section{ANEXO 3}

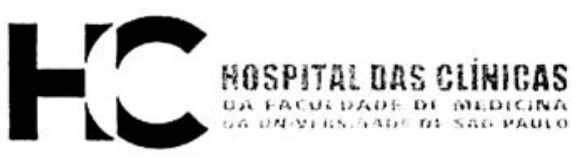

\section{APROVAÇÃO}

A Comissão de Ética para Análise de Projetos de Pesquisa - CAPPesq da Diretoria Clínica do Hospital das Clínicas e da Faculdade de Medicina da Universidade de São Paulo, em sessão de 23.02.06, APROVOU o Protocolo de Pesquisa $n^{\circ} 1283 / 05$, intitulado: "Avaliação vocal em pacientes portadores de obesidade mórbida submetidos à cirurgia bariátrica." apresentado pelo Departamento de GASTROENTEROLOGIA, inclusive o Termo de Consentimento Livre e Esclarecido.

$$
\text { Cabe ao pesquisador elaborar e apresentar à }
$$

CAPPesq, os relatórios parciais e final sobre a pesquisa (Resolução do Conselho Nacional de Saúde $n^{\circ} 196$, de 10.10.1996, inciso IX. 2, letra "c")

Pesquisador(a) Responsável: Prof. Dr. Bruno Zilberstein

Pesquisador(a) Executante: Sra. Maria Gabriela Bernado da Cunha

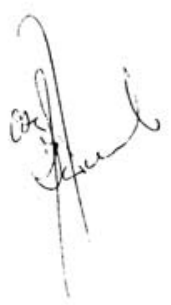

CAPPesq, 23 de Fevereiro de 2006.

$$
\text { Chuld corllo }
$$

PROF. DR. EUCLIDES AYRES DE CASTILHO

Presidente da Comissão de Ética para Análise de Projetos de Pesquisa

\footnotetext{
Comissão de Ética para Análise de Projetos de Pesquisa do HCFMUSP e da FMUSP Diretoria Clínica do Hospital das Clinicas da Faculdade de Medicina da Universidade de São Paulo Rua Ovidio Pires de Campos. 225, $5^{\circ}$ andar - CEP 05430010 - São Paulo - SP 
ANEXO 4

\section{ANÁLISE ACÚSTICA}

Indivíduo número:

\section{Medidas}
"Jitter":
( ) Normal
( ) Alterado
"Shimmer"
( ) Normal
( ) Alterado
Ruído
( ) Normal
( ) Alterado

Fo:

TMF: 
ANEXO 5

\section{ANÁLISE PERCEPTIVO-AUDITIVA}

Indivíduo número:

Fonoaudióloga:

$\begin{array}{lllll}\mathbf{G}= & 0 & 1 & 2 & 3 \\ \mathbf{I}= & 0 & 1 & 2 & 3 \\ \mathbf{R}= & 0 & 1 & 2 & 3 \\ \mathbf{B}= & 0 & 1 & 2 & 3 \\ \mathbf{A}= & 0 & 1 & 2 & 3 \\ \mathbf{S}= & 0 & 1 & 2 & 3\end{array}$

Final da emissão em "Vocal Fry" = $\mathrm{S}$ ou $\mathrm{N}$

Estrangulamento ao final da emissão $=S$ ou $N$

Ressonância= Equilibrada( ) Hipernasal( ) Hiponasal( ) Faríngea( ) Laringo-faríngea( ) 
ANEXO 6

\section{AVALIACẼ̃O LARINGOLÓGICA}

Indivíduo número:

Laringologista:

Laringoscopia

Normal

Alterada

Cisto de PV

AEM não especificada

( )

Vasculodisgenesia

( )

Cordite

Espessamento Nodular

( )

Granuloma de processo vocal

Hipertrofia de banda ventricular

Úlceras de Pênfigo Vulgar

Sulco de PV

Pólipo de PV

Edema de Reinke

Sinais laríngeos sugestivos de lesão por RGE S( ) N( ) 